\title{
Tau depletion prevents progressive blood-brain barrier damage in a mouse model of tauopathy
}

\author{
Laura J Blair ${ }^{1,2}$, Haley D Frauen ${ }^{1}$, Bo Zhang ${ }^{1,2}$, Bryce A Nordhues ${ }^{1,2}$, Sara Bijan ${ }^{1}$, Yen-Chi Lin ${ }^{1}$, Frank Zamudio ${ }^{1}$, \\ Lidice D Hernandez ${ }^{1}$, Jonathan J Sabbagh ${ }^{1,2}$, Maj-Linda B Selenica ${ }^{3}$ and Chad A Dickey ${ }^{1,2^{*}}$
}

\begin{abstract}
Introduction: The blood-brain barrier (BBB) is damaged in tauopathies, including progressive supranuclear palsy (PSP) and Alzheimer's disease (AD), which is thought to contribute to pathogenesis later in the disease course. In $A D, B B B$ dysfunction has been associated with amyloid beta $(A B)$ pathology, but the role of tau in this process is not well characterized. Since increased BBB permeability is found in tauopathies without Aß pathology, like PSP, we suspected that tau accumulation alone could not only be sufficient, but even more important than AB for BBB damage.

Results: Longitudinal evaluation of brain tissue from the tetracycline-regulatable rTg4510 tau transgenic mouse model showed progressive lgG, T cell and red blood cell infiltration. The Evans blue (EB) dye that is excluded from the brain when the BBB is intact also permeated the brains of $r$ Tg4510 mice following peripheral administration, indicative of a bonafide BBB defect, but this was only evident later in life. Thus, despite the marked brain atrophy and inflammation that occurs earlier in this model, BBB integrity is maintained. Interestingly, BBB dysfunction emerged at the same time that perivascular tau emerged around major hippocampal blood vessels. However, when tau expression was suppressed using doxycycline, BBB integrity was preserved, suggesting that the BBB can be stabilized in a tauopathic brain by reducing tau levels.

Conclusions: For the first time, these data demonstrate that tau alone can initiate breakdown of the BBB, but the $\mathrm{BBB}$ is remarkably resilient, maintaining its integrity in the face of marked brain atrophy, neuroinflammation and toxic tau accumulation. Moreover, the BBB can recover integrity when tau levels are reduced. Thus, late stage interventions targeting tau may slow the vascular contributions to cognitive impairment and dementia that occur in tauopathies.
\end{abstract}

Keywords: rTg4510, Alzheimer's disease, Blood-brain barrier, Tau, Vascular

\section{Introduction}

The blood-brain barrier (BBB) is a physical barrier of endothelial cells, supported by astrocytes, that selectively limits the passage of peripheral blood components and pathogens into the brain, while allowing the passage of essential nutrients [1,2]. In aging, there is a decline in the stability of the $\mathrm{BBB}$ leading to increased permeability [3]. This disruption of $\mathrm{BBB}$ integrity is exacerbated in Alzheimer's disease (AD) [4-6], allowing peripheral

\footnotetext{
* Correspondence: cdickey@health.usf.edu

'Department of Molecular Medicine, University of South Florida, Byrd

Alzheimer's Institute, 4001 E. Fletcher Ave MDC 36, Tampa, FL 33613, USA

2James A. Haley Veteran's Hospital, 13000 Bruce B. Downs Blvd., Tampa, FL

33612, USA

Full list of author information is available at the end of the article
}

immune cells access to the brain and perhaps exacerbating pathology by promoting detrimental neuroinflammation [7-10]. Most evidence suggests that this increase in $\mathrm{BBB}$ damage is driven by accumulation of amyloid-beta $(A ß)$, particularly along the vasculature [11-13]. However, the microtubule associated protein tau has been shown to accumulate as puncta in perivascular spaces in sporadic $A D$ with cerebral amyloid angiopathy (CAA) [14]. BBB damage is also observed in tauopathies that lack $A ß$ over-production [15-17], suggesting a role for tau in BBB damage [18-21], although this has yet to be proven.

We turned to the well-characterized tetracycline inducible rTg4510 mouse model to address the gaps in our knowledge about the role of tau in BBB damage. These 
mice exhibit a robust pathological profile, which includes tau tangle formation, neuroinflammation, neuronal loss and cognitive deficits [22-24]. Overall tau accumulation is detectable by 1 month of age, while insoluble tau, neurotoxicity, and atrophy, appear as early as 2.5 months of age [22]. These pathologies progressively worsen and by 8.5 months of age, roughly $80 \%$ of neurons in the CA 1 and dentate gyrus are lost [22,24-27]. Importantly, tau expression can be suppressed by doxycycline (DOX) administration in this model, a feature that can be exploited to determine whether pathophysiological consequences of tau expression can be halted. For example, tau suppression was previously found to rescue memory deficits and neuronal loss in this model, without affecting the accumulation of neurofibrillary tangles [23].

Thus, we used this model to determine if and when BBB integrity might be compromised, and whether this was caused by tau accumulation alone, by brain volume loss, or by some other pathology yet to be described. We also exploited the DOX-regulation of this model to determine if BBB damage was permanent, and whether specific features of the model were most closely linked to $\mathrm{BBB}$ dysfunction. We found that tau accumulation does eventually lead to $B B B$ disruption, but there is an extremely high threshold of neuronal loss that the $\mathrm{BBB}$ can withstand before losing integrity. In fact, onset of BBB disruption was concomitant with the appearance of perivascular tau, suggesting a relationship between these two pathologies. BBB function was largely restored when tau was suppressed, even well after onset of BBB dysfunction. These data suggest that tau accumulation can disrupt BBB integrity and that BBB dysfunction coincides with the appearance of perivascular tau. These findings are important considerations for drug discovery efforts based on this model because they suggest that the vasculature can recover when tau levels are reduced, suggesting that late stage interventions targeting tau may be useful for slowing the vascular contributions to cognitive impairment and dementia that occur in tauopathies.

\section{Materials and methods}

\section{Study approval}

All applicable international, national, and/or institutional guidelines for the care and use of animals were followed. All animal handling and procedures were carried out in accordance with the University of South Florida's Institutional Animal Care and Use Committee (IACUC) in accordance with the Association for Assessment and Accreditation of Laboratory Animal Care International (AALAC) regulations.

\section{Mouse colony and tissue processing}

The rTg4510 colony was bred and maintained as previously described [22,23]. Mice were harvested at 1-, 3-, 6-, 9-, and 12-months old ( $\mathrm{N}=5-8$ per genotype). At sacrifice, mice were perfused with $0.9 \%$ saline solution; brains were rapidly removed and fixed with $4 \%$ paraformaldehyde overnight. Following sucrose gradients up to $30 \%$, tissue was sectioned using a sliding microtome at a thickness of $25 \mu \mathrm{m}$.

\section{Doxycycline treatment procedure}

In the DOX treated groups, 10.5- to 11-month old $\mathrm{rTg} 4510(\mathrm{~N}=7)$ and wild-type $(\mathrm{N}=7)$ mice were treated for $\sim 5$ weeks with DOX and harvested at 12-months old. When DOX treatment was started, mice were given $1.5 \mathrm{~g} / \mathrm{L}$ DOX (Sigma Cat\# 9891, St. Louis, MO;) in 4\% sucrose water for 48 hours. After two days, DOX water was replaced by tap water and mice were fed a DOX diet containing $0.2 \mathrm{~g} / \mathrm{kg}$ DOX (Harlan Cat\# TD.00502, Indianapolis, IN) until sacrifice.

\section{Intracardiac injection of Evans blue (EB)}

Intracardiac injection of EB (Sigma) was performed on 6- $(\mathrm{N}=7)$, 9- $(\mathrm{N}=8), 12-(\mathrm{N}=8)$, and 12-month old DOX-treated $(\mathrm{N}=7) \mathrm{rTg} 4510$ and wild-type littermates as previously described [28], with slight modification. Mice were anesthetized by inhalation of precisely $2 \%$ isoflurane, to prevent variance of BBB opening due to isoflurane inhalation [29]. While in dorsal recumbency, hair was removed from the injection site, the site was sterilized, and a percutaneous stick was made through the rib cage between the $4^{\text {th }}$ and $5^{\text {th }}$ intercostal space from the mouse's left side. $20 \mathrm{mg} / \mathrm{kg} \mathrm{EB}$ in sterile PBS was injected into the left ventricle at a rate of approximately $200 \mu \mathrm{L} / \mathrm{min}$ forty minutes before sacrifice. Tissue was harvested as describe above, including transcardiac perfusion to remove all blood from blood vessels.

\section{Immunohistochemistry and immunofluorescence}

Tissue was stained free floating as previously described [30] with minor modifications using antibodies directed against tau (H-150) (Santa Cruz, Dallas, Tx; 1:5000), heat shock protein 27 kDa (Hsp27; c-20) (Santa Cruz; 1:5000), Glial fibrillary acidic protein (GFAP; DAKO, Carpinteria, $\mathrm{CA}$; 1:3000), $\mathrm{CD}^{+}$(AbD serotec, Raleigh, NC; 1:30,000), and $\mathrm{CD}_{4}^{+}$(AbD serotec; 1:30,000) with swine anti-goat IgG BIOT (1:200), goat anti-rabbit IgG BIOT $(1: 10,000)$, goat anti-mouse IgG BIOT (1:3000) and goat anti-rat IgG BIOT (1:1000) secondary antibodies (Southern Biotech, Birmingham, AL). Blood vessels were stained using DyLight 488 labeled Lycopersicon Esculetum (Tomato) Lectin (Vector Laboratories; Burlingame CA; 1:200). Fluorescently stained tissues were stained free-floating as previously described [31]. Briefly, following permeabilization, tissue was incubated with tau (H-150; 1:1000) and/or Hsp27 (1:100) primary antibody overnight. Following PBS washes, tissue was incubated with Alexa Fluor 488 donkey anti-goat IgG (Invitrogen, Grand Island, NY; 
1:1000) and/or Alexa Fluor 633 goat anti-rabbit IgG (Invitrogen; 1:1000) secondary antibody for 2 hours, followed by an overnight incubation with Tomato Lectin 488 (1:500). Brightfield tissue was mounted, dehydrated, and coverslipped using DPX (VWR, Atlanta, GA). Fluorescently stained tissue was mounted and then coverslipped using ProLong Gold Antifade Reagent (Invitrogen). Hematoxylin (Sigma) and eosin (Sigma) $(\mathrm{H} \& \mathrm{E})$ staining was performed on mounted tissue as previously described [32] to view red blood cells (RBCs). Following nuclear and cytoplasmic staining, tissue was rapidly dehydrated in ethanol gradients, cleared in xylenes, and coverslipped using DPX.

\section{Tissue imaging and quantification}

Stained tissue was imaged using a Mirax slide scanner. IgG, tau (H-150), Hsp27, and GFAP were quantified in the cortex and hippocampus by segmentation of positive areas using NearCYTE software. As previously reported, this software allows for the segmentation of positive staining based on hue, saturation, and color intensity compared to that of the background in very specific regions of the tissue $[33,34]$. Consistent color settings were used to analyze each piece of tissue, which was selected for regions of interest based on a mouse brain atlas, across each stain. $\mathrm{CD}^{+}$and $\mathrm{CD}^{+} \mathrm{T}$ cells along with $\mathrm{H} \& \mathrm{E}$ positive red blood cells were manually counted by a blinded investigator throughout each section.

For Lectin/tau staining images, z-stack images were taken each $1 \mu \mathrm{m}$ through the tissue using Leica TCS SP2 Confocal Microscope equipped with a 63x/ 1.4-0.60 PLAN APO Oil objective using Argon and Red HeNe lasers and I3 and N2.1 filters respectively. EB and Hsp27/ tau stain was imaged with an AxioCamMR3 camera on a Zeiss Axiolmage.Z1 using a $10 \times / 0.25$ dry Zeiss EC Plan-Neofluar $10 \times / 0.30$ M27 objective. Positive signal was excited using an EXFO X-Cite fluorescence illuminator with 43HE: Cy3 filter (excitation 550/emission 605) at a set exposure time of $750 \mathrm{~ms}$ for all tissue. Analysis of EB images was performed using ImageJ software (National Institutes of Health). Images were converted to 8-bit and a threshold of 100-255 was applied. Particle analysis was performed on areas between 0 and infinity pixels $^{2}$ and a circularity of $0.50-1.00$, which allowed for the analysis of all positive EB staining.

\section{Image analysis and statistics}

Six to eight sections per mouse were averaged together as a single representative value for a brain region. Statistical analysis was performed either using a 1-way or 2way analysis of variance (ANOVA) (Age and Genotype) or (Age and Treatment) as appropriate. Values compared between genotypes of a single age group were analyzed by t-test. Values were considered significant when $p<0.05$. Graphs were generated using GraphPad Prism 5.0.

\section{Results}

\section{IgG extravasation in aged $\mathbf{r T g} 4510$ mice}

The first indication that there could be BBB damage in the rTg4510 mouse model was the presence of intense background staining when using anti-mouse IgG secondary antibodies on aged tissue, similar to what has previously been shown following AAV delivery of P301L tau in wild-type mice $[19,20]$. This anti-IgG reactivity was only observed in aged rTg4510 and not in agematched wild-type littermates or younger rTg4510 mice. To investigate the progression and severity of the IgG infiltration, a more thorough examination of IgG immunoreactivity was then performed on rTg4510 and wildtype mice at 1-, 3-, 6-, 9-, and 12-months old. We found that rTg4510 mice displayed progressively higher visible levels of anti-mouse IgG immunoreactivity than agematched wild-type littermate (Figure 1a). The most visibly apparent regions affected by IgG accumulation were the hippocampus, stemming from the fimbria of the hippocampus, and the frontal cortex, most notably along the edges of the tissue. Both the hippocampus and frontal cortex have been characterized to have extensive tau accumulation and severe neuron loss in rTg4510 model [24]. In fact, the hippocampus has been shown in wild-type rodents to be susceptible to BBB impairment $[35,36]$, so this natural predisposition combined with the intense pathology which is found throughout the hippocampus made this region particularly interesting. Antimouse IgG quantification in the hippocampus revealed a significant increase in 12-month old rTg4510 mice (Figure 1b) compared to age-matched wild-type mice. This same phenomenon was mirrored in previous studies using hippocampal tissue of $\mathrm{AD}$ cases [5]. Upon closer visual examination of the hippocampus in rTg4510 mice, the highest accumulation of IgG was found in the CA3 (Figure 1c), however the dentate gyrus and the CA1 region were also noticeably darker than the wild-type littermates. Although a similar pattern of staining were seen in the hippocampus of the wild-type mice, the overall staining was much lighter than that found in the rTg4510 model. Since regions adjacent to periventricular areas are most prone to BBB permeability, it was not surprising the CA3 region had the most IgG immunoreactivity [37]. In the frontal cortex, another region that has significant tau accumulation and atrophy [38], IgG immunoreactivity was also significantly increased in 12-month old rTg4510 mice compared to wild-type littermates (Figure 1d and e). This immunoreactivity was most marked on the edge of the tissue with a gradient to lighter IgG reactivity radiating laterally inward. Based on these findings, we speculated aging, 


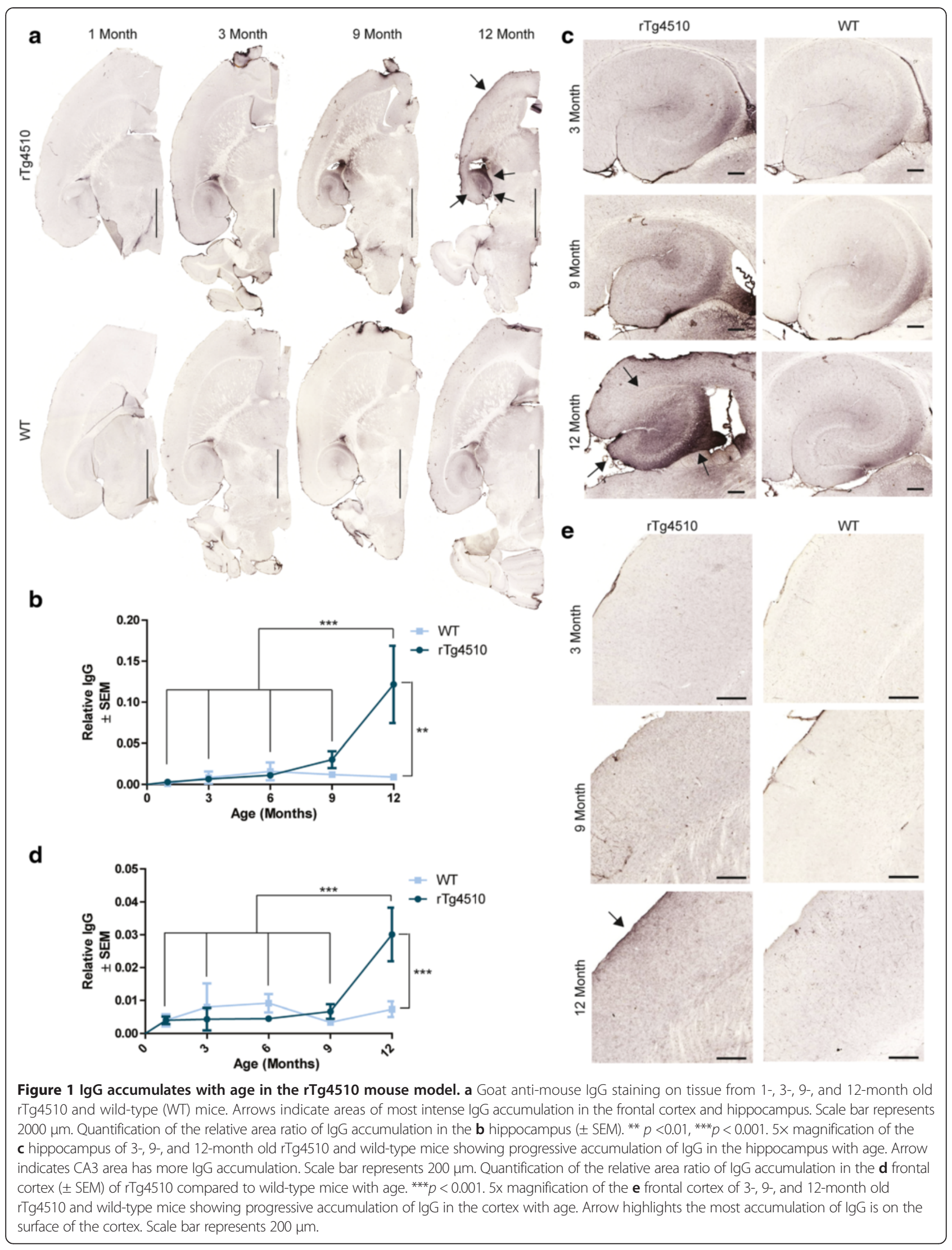


combined with chronic tau overexpression, could lead to BBB disruption.

\section{Extravasation of immunoglobulin and EB in 12-month old rTg4510 mice}

To more thoroughly investigate $\mathrm{BBB}$ permeability in these mice, three cohorts of $\mathrm{rTg} 4510$ mice and wild-type littermates aged 6-, 9-, and 12-months old were intracardially injected with $E B$, a dye that is typically occluded from the brain except when the BBB is damaged. EB is commonly used for BBB studies and emits fluorescence when bound to albumin in the blood [39-41]. Mice were perfused to remove all blood from the brain. Thus any fluorescent signal in the brain would indicate EB bound to albumin in the parenchyma and not the surrounding vasculature, indicative of $\mathrm{BBB}$ breakdown. Whole brains from mice that received intracardiac EB injections were imaged following sacrifice (Figure 2a). Blue staining was visible in each of the 12-month old rTg4510 tau mice predominantly in the cortical layers superior to the

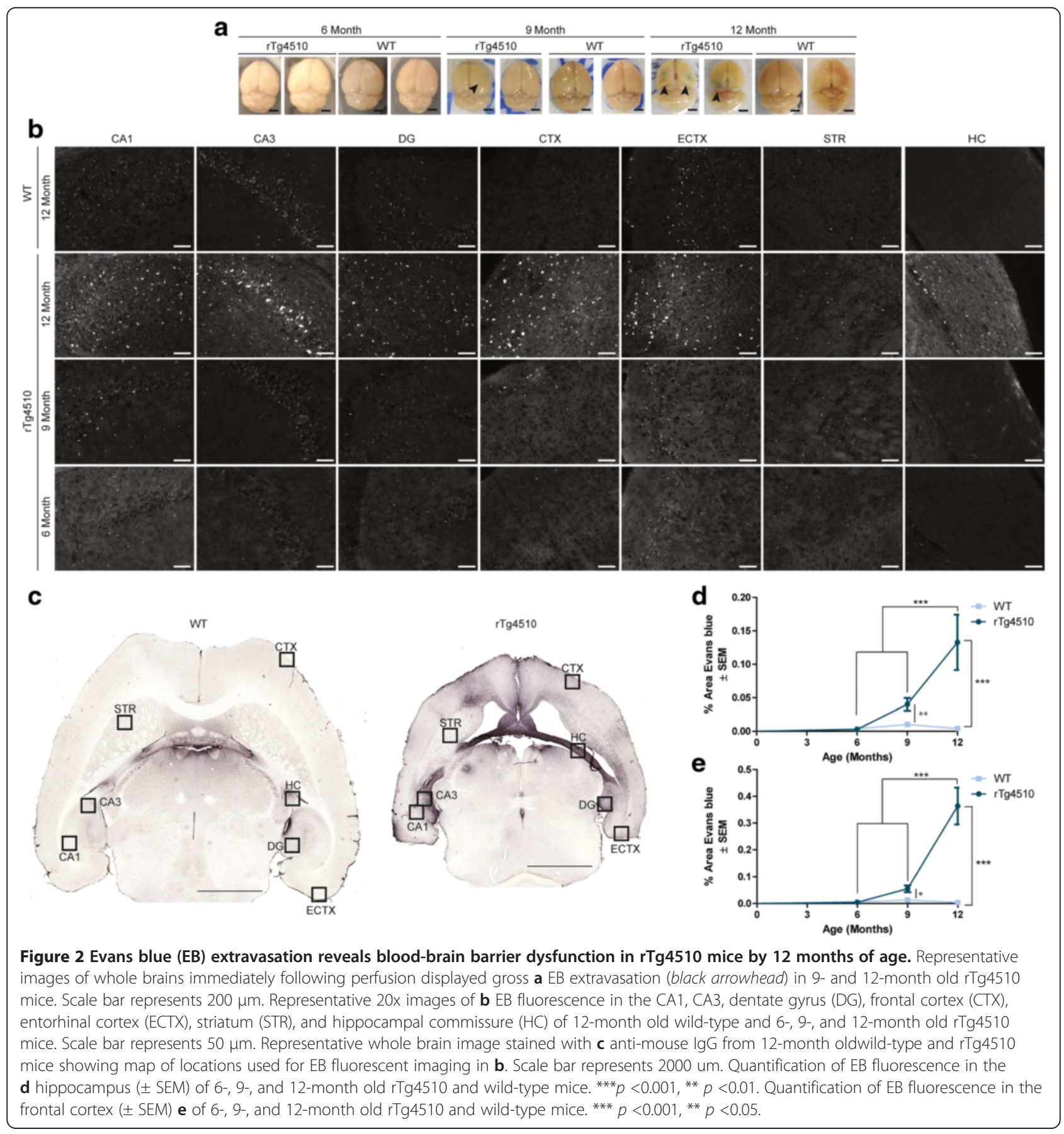


hippocampus, similar to the pattern of accumulation of IgG on the surface of the cortex (Figure 1e). This blue staining was not visible in 6-month old rTg4510 mice or 12-month old wild-type littermates, but was seen to a lesser extent in some 9-month old rTg4510 mice.

Brain tissue was fixed, sectioned, and mounted for brain region specific analysis of EB. EB fluorescence was found to be highest in 12-month old rTg4510 mice, compared to younger rTg4510 mice or age-matched wild-type mice (Figure 2b). Regions with high EB expression corresponded to those with greatest anti-mouse IgG immunoreactivity (Figure 2c), the highest being the hippocampus and the cortex, followed by the entorhinal cortex and hippocampal commissure. This again shows that periventricular regions are most susceptible to $\mathrm{BBB}$ dysfunction [37], and that this is severely exacerbated in the rTg4510 mouse model. Thus, we analyzed the extravasation of EB in the hippocampus and frontal cortex, since these areas showed prominent IgG infiltration. Significant EB fluorescence was observed in the hippocampus (Figure 2d) and frontal cortex (Figure 2e) of 12-month old rTg4510 mice but not in 6-month old rTg4510 mice or any wild-type mice. Similar to IgG, extravasation of EB was greatest in the CA3 region of the hippocampus (Additional file 1: Figure S1), compared to the CA1 and dentate gyrus, however both of these regions still showed significant EB accumulation. 9-month old rTg4510 mice showed high levels of EB fluorescence in both the hippocampus and frontal cortex which were significant by Student t-test, but not ANOVA. Thus rTg4510 mice can develop a major BBB defect, but this is only significant after 9 months of age, well after robust brain atrophy and tau accumulation begins in this model.

\section{Increasing tau accumulation is accompanied by glial activation}

As previously reported [22,23,42], tau accumulation was significantly increased in an age-dependent manner in the hippocampus (Figure 3a) and frontal cortex (Figure 3b) of rTg4510 mice. Tau accumulation throughout the brain accompanied by visible brain atrophy, including the hippocampus (Additional file 1: Figure S2), was progressively increased in mice from 6 to 12 months of age (Figure 3c). Tau staining in the hippocampus (Figure 3d) and frontal cortex (Figure 3e) showed region-specific increases in tau accumulation with age.

It is well-documented that tau accumulation in the rTg4510 mouse model induces neuroinflammation, including microgliosis and astrocytosis [24,30,32,43]. In fact, there is a robust inflammatory response that begins somewhere between 2 and 4 months of age in these mice [43]. This inflammation is closely correlated with neurodegeneration in this model and can be reversed by
DOX-treatment $[20,38,43]$. Here we focused on astrocytosis rather than microgliosis given the intimate role of astrocytes with BBB stability [44]. We investigated the levels and morphology of heat shock protein $27 \mathrm{kDa}$ (Hsp27) in 6-, 9-, and 12-month old rTg4510 and agematched wild-type mice. Hsp27 was selected because it has been shown to increase with age [22], is highly expressed in activated astrocytes [45], is found lining blood vessels [46], is constitutively expressed in vascular endothelial cells [47], and has been implicated in regulation of the BBB through its role in actin stabilization [48]. We found that Hsp27 levels in the hippocampus (Figure 4a) and frontal cortex (Figure 4b) were significantly increased in $\mathrm{rTg} 4510$ mice at 12 months of age. This progressive increase was clearly visible throughout entire brain sections (Figure 4c). Upon closer examination of the hippocampus (Figure 4d) and frontal cortex (Figure 4e), Hsp27 immunoreactivity appeared adjacent to blood vessels and with age these astrocytes appeared more activated (Figure 4f). The age-related increases in Hsp27 were significantly exacerbated by tau overexpression (Figure 4a and b).

To confirm the accumulation of astrocytes as detected by Hsp27 staining, we also stained tissue from 6-, 9-, and 12-month old rTg4510 and wild-type mice for GFAP, a more traditional marker of astrocytes $[18,49,50]$. Similar to the results from Hsp27, GFAP was significantly elevated in the hippocampus (Figure 5a) and frontal cortex (Figure $5 \mathrm{~b}$ ) of aged rTg4510 mice compared to wild-type controls. Whole brain sections show that accumulation of GFAP followed a similar pattern to that of tau in the rTg4510 mice (Figure 5c). Closer examination of the hippocampus (Figure 5d) showed that there was an age related increase in GFAP immunoreactivity that was exacerbated in the rTg4510 mice starting at 9 months of age, significantly higher than wild-type mice. While the rTg4510 cortex (Figure 5e) showed less of an agerelated increase in GFAP immunoreactivity, there was still a clear elevation starting at 6 months of age that progressively increased.

\section{Invasion of red blood cells and T cell lymphocytes is evident in aged rTg4510 mice}

Blood component infiltration into the brains of aged rTg4510 mice suggested impaired BBB integrity. Therefore, we sought to determine if whole peripheral blood cells could also enter the parenchyma with age. Brain sections from 6-, 9-, and 12-month old rTg4510 mice were stained with hematoxylin and eosin (H\&E) to visualize red blood cells (RBCs; erythrocytes) that remained in the brain parenchyma following perfusion [51]. RBCs, which are highly eosinophilic, stain bright red with circular morphology void of blue nuclear staining by $H \& E$ staining. These RBCs were manually counted throughout at least 6 


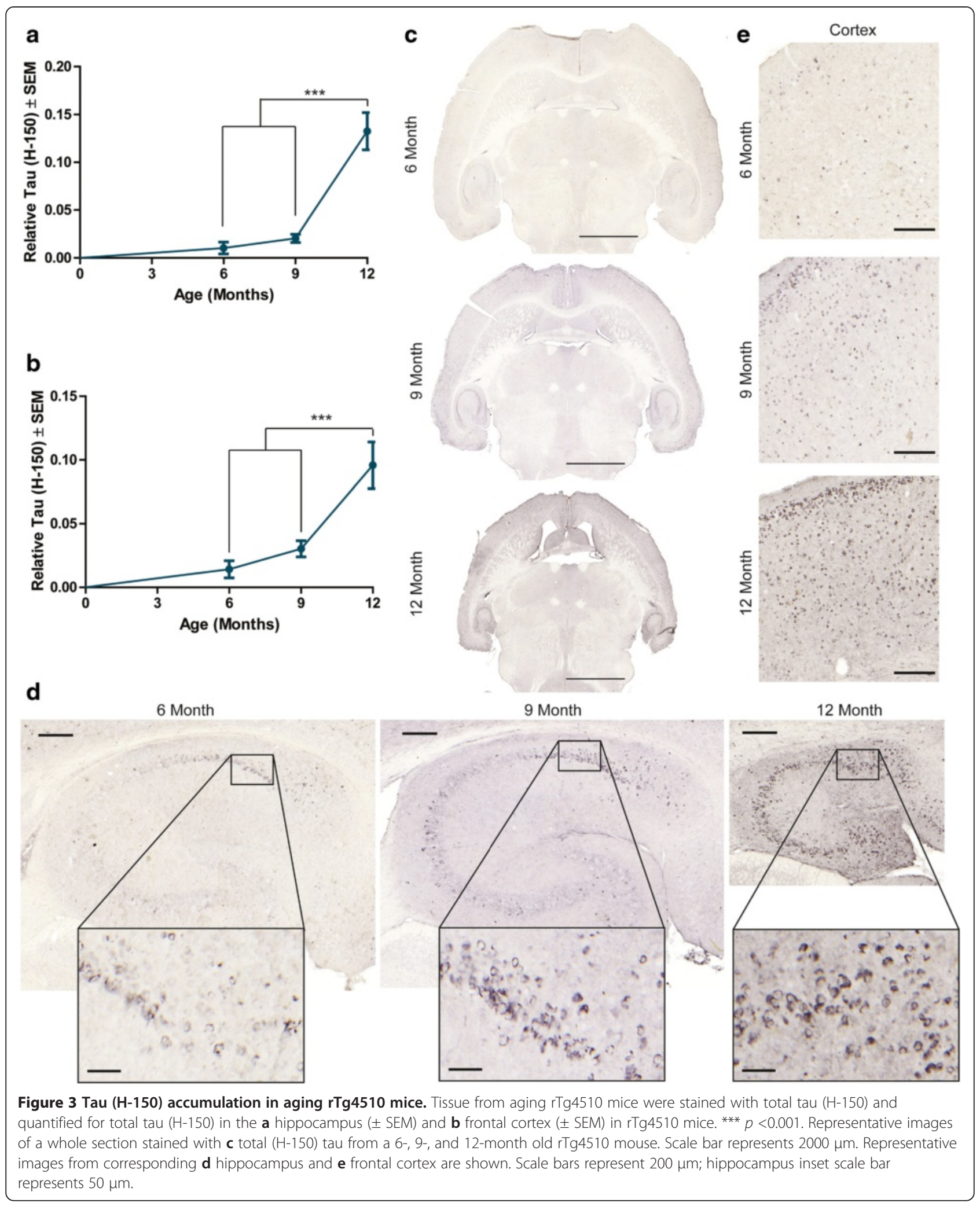

sections from each mouse in the 6-, 9-, and 12-month old cohorts. Significantly more RBCs were found in the rTg4510 parenchyma at 12 months of age (Figure 6a, b).
RBCs appeared to infiltrate the tissue near ventricles, the outer edges of the cortex, and along vasculature, particularly in the hippocampus. 


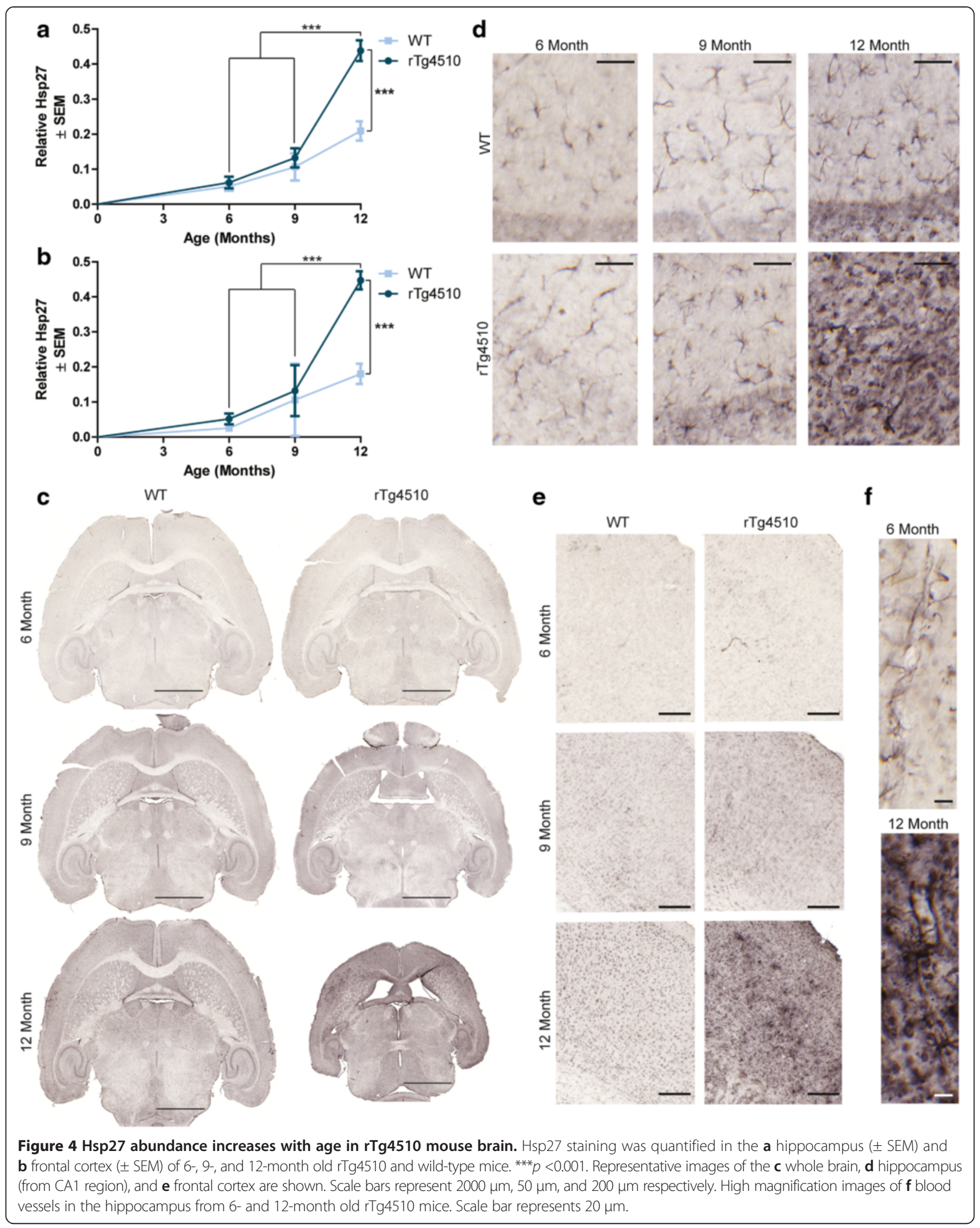




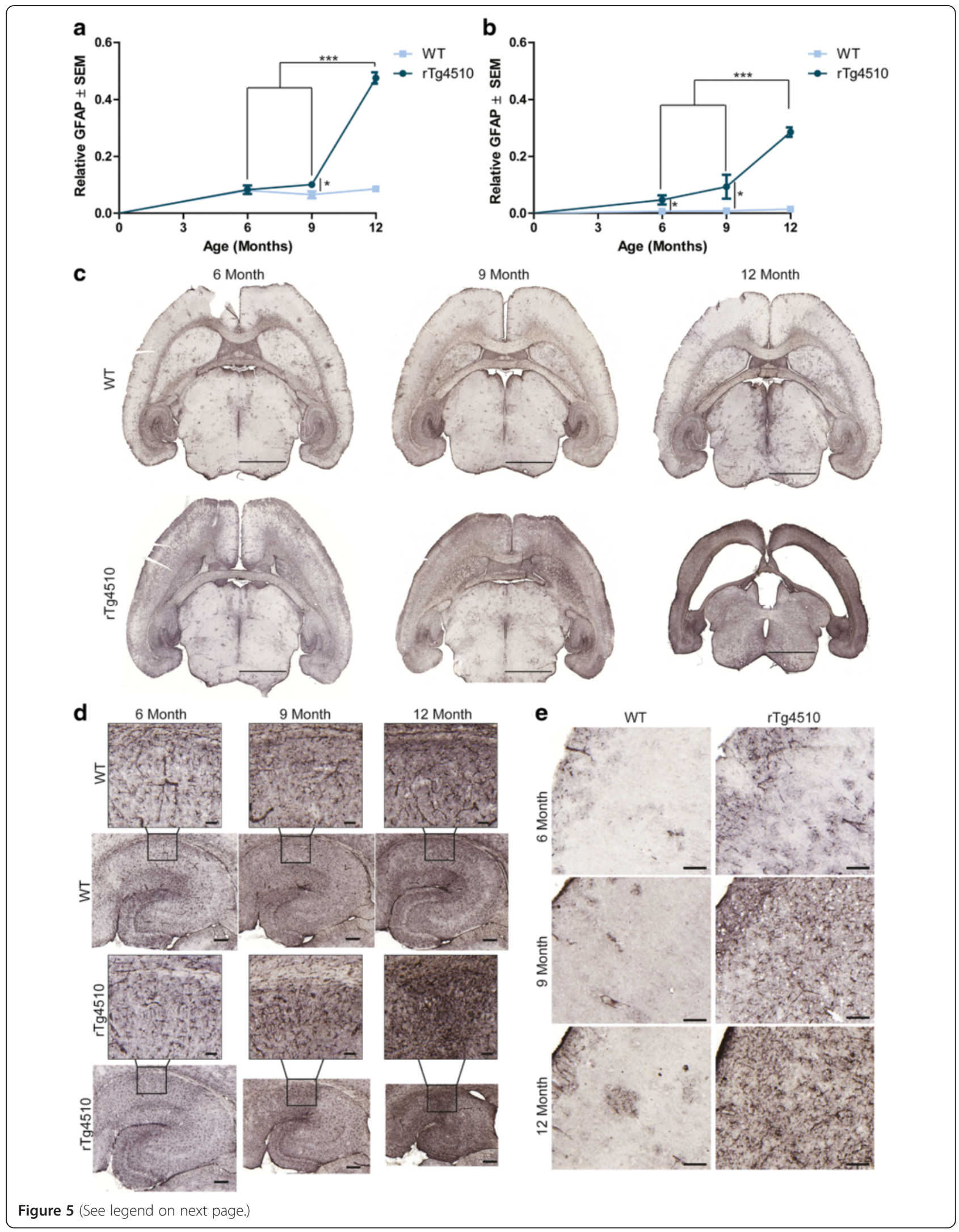


(See figure on previous page.)

Figure 5 GFAP positive astrocytes accumulate with age in rTg4510 mice. Area ratio positive for GFAP immunoreactivity was quantified in the a hippocampus ( \pm SEM) $\left({ }^{*} p=0.01696 ;{ }^{* * *} p<0.001\right)$ and $\mathbf{b}$ frontal cortex $\left( \pm\right.$ SEM) $\left(6\right.$-month ${ }^{*} p=0.020102,9$ month $\left.{ }^{*} p=0.04813,{ }^{* * *} p<0.001\right)$ of wild-type and rTg4510 mice at 6, 9 and 12 months of age; c representative whole brain images are shown. Scale bar represents $2000 \mu \mathrm{m}$. Representative images of $\mathbf{d}$ hippocampus ( \pm SEM) and e cortex $( \pm$ SEM) of GFAP immunostained tissue from 6-, 9- and 12-month old wild-type and $\mathrm{rTg} 4510$ mice. Scale bar represents $100 \mu \mathrm{m}$; inset scale represents $20 \mu \mathrm{m}$.

As BBB defects are often correlated with entry of immune cells into the brain, staining for $\mathrm{CD}^{+} \mathrm{T}$ cells was performed. $\mathrm{CD}^{+} \mathrm{T}$ cells significantly infiltrated the brain of 12-month old rTg4510 mice (Figure 6c), especially near the longitudinal hippocampal blood vessels (internal transverse hippocampal artery and/or vein; Figure $6 \mathrm{~d}$ ) and periventricular to the lateral ventricles (Figure 6e), but were rarely observed in age-matched wild-type mice (Figure 6f). CD4 ${ }^{+} \mathrm{T}$ cells were also found to significantly infiltrate the brains of 12-month old rTg4510 (Figure 6g) mice compared to their younger counterparts and to age-matched wild-type mice. The infiltration of these $\mathrm{CD} 4^{+} \mathrm{T}$ cells were found in similar regions as $\mathrm{CD}^{+} \mathrm{T}$ cells, along the longitudinal hippocampal blood vessels (Figure $6 \mathrm{~h}$ ) and near periventricular regions (Figure $6 \mathbf{i}$ and $\mathbf{j}$ ). Taken together, these data

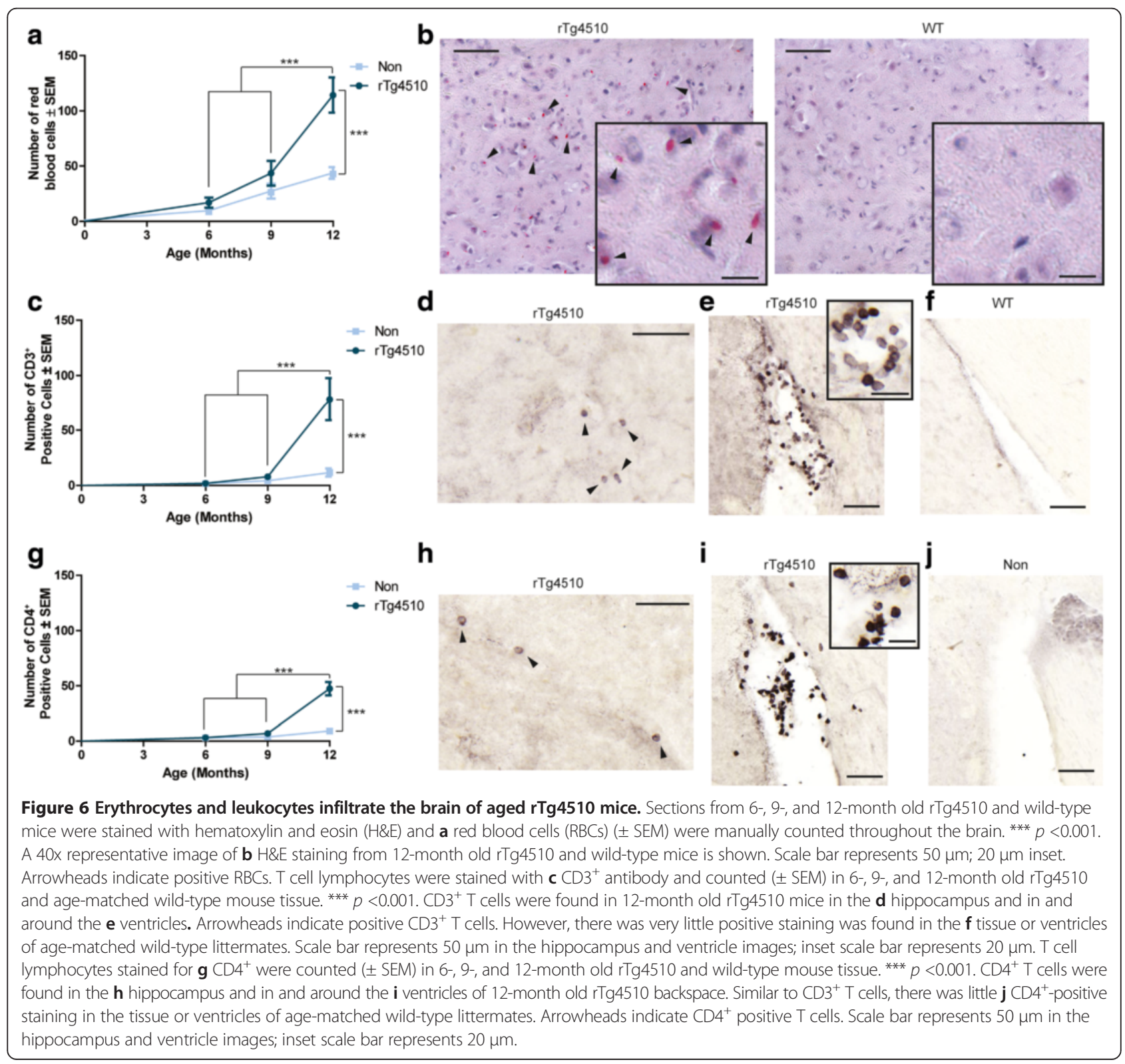




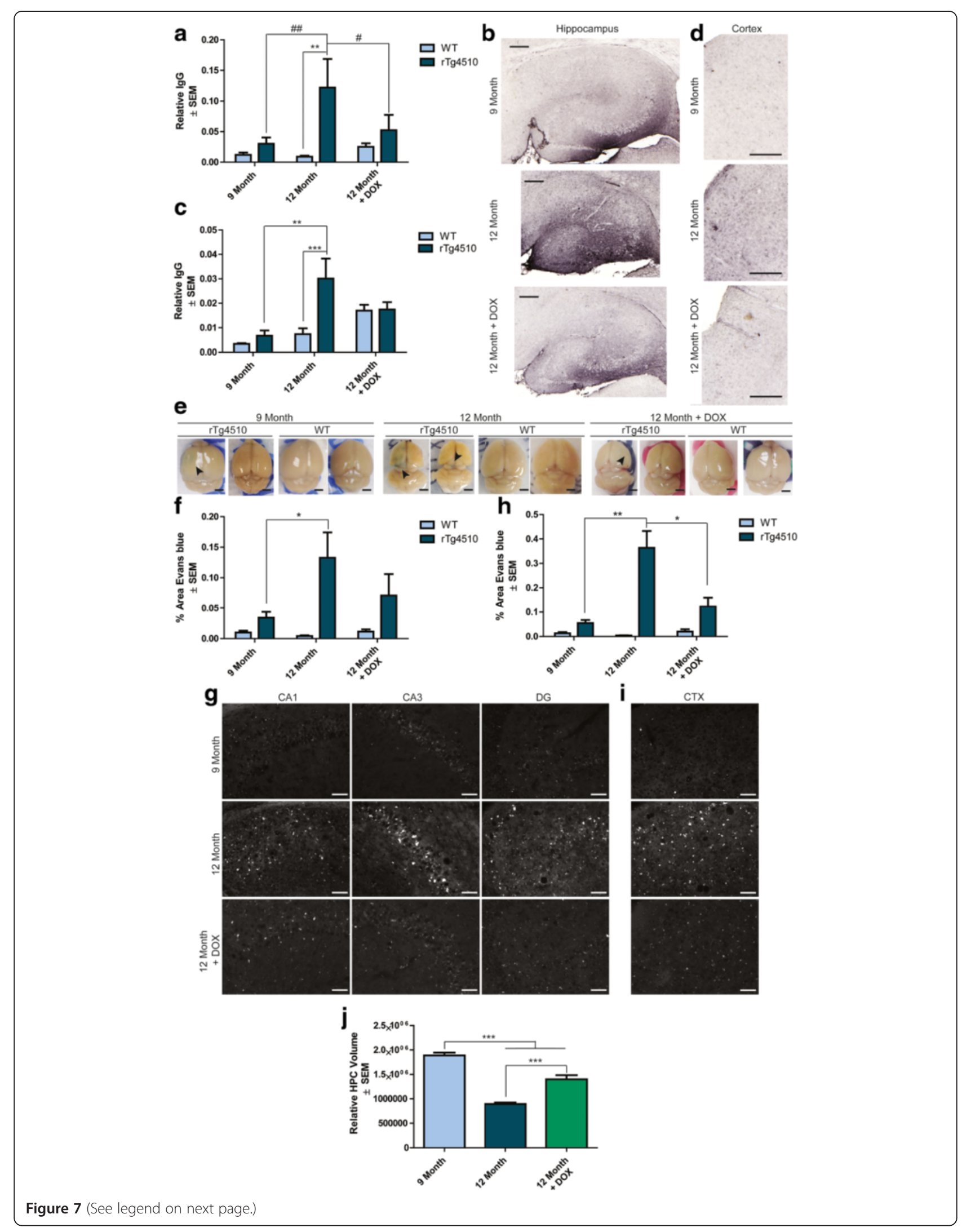


(See figure on previous page.)

Figure 7 Tau suppression by DOX slows BBB defect in 12-month old rTg4510 mice. IgG levels in the (a and b) hippocampus ( \pm SEM) and (c and d) frontal cortex ( \pm SEM) of 12-month old DOX-treated mice compared to 9- and 12-month old wild-type and rTg4510 mice; Representative images are shown. ${ }^{* *} p<0.001,{ }^{* *} p<0.01$. Scale bar represents $200 \mu \mathrm{m}$. Images of e whole brains immediately following perfusion to observe Evans blue (EB) (black arrowhead) in 12 month DOX-treated mice compared to 9 and 12 month old rTg4510 relative to matching wild-type mice. Scale bar represents $200 \mu \mathrm{m}$. Positive EB expression was measured in the (f and g) hippocampus ( \pm SEM) and (h and i) frontal cortex ( \pm SEM) of 12 month old DOX-treated mice compared to 9- and 12-month old rTg4510 and age-matched wild-type mice; representative images of 9-month old, 12-month old, and DOX-treated 12-month old mice are shown. ${ }^{*} p<0.05^{* *}, p<0.01$. Scale bar represents $50 \mu m$. Relative $\mathbf{j}$ hippocampal brain volume $( \pm$ SEM) in 9- and 12-month old rTg4510 mice compared to 12-month old rTg4510 mice treated with DOX. ${ }^{* * *} p<0.001$.

show that BBB disruption in 12-month old rTg4510 mice is sufficient to not only allow blood components into the brain, but also whole blood cells.

\section{Tau suppression by doxycycline restores BBB integrity}

We next sought to test the resiliency of the BBB to damage caused by tau accumulation. We took advantage of the ability to suppress tau expression in the rTg4510 model using DOX feed. DOX was fed to 10.5- and 11month old rTg4510 and wild-type mice for $\sim 5$ weeks. At 12 months of age, mice were injected with EB forty minutes before perfusion and tissue was collected following this in an identical manner to the cohorts described above. Immunostaining revealed that the levels of IgG were lower in 12-month old rTg4510 mice that received DOX treatment compared to the untreated group. In fact, the IgG immunoreactivity in the hippocampus (Figure 7a and b) and frontal cortex (Figure 7c and d) of mice treated with DOX beginning at $\sim 11$ months was indistinguishable from 9-month old rTg4510 mice, suggesting that tau suppression by DOX could slow and possibly reverse the $\mathrm{BBB}$ dysfunction in these mice. Superficial examination of EB staining also suggested that DOX-treated 12-month old rTg4510 mice resembled 9-month old rTg4510 mice with regard to EB extravasation (Figure 7e). Histochemical analysis of the area ratio of EB extravasation in these mice showed that the hippocampi of 12-month old DOX-treated rTg4510 mice were quantitatively indistinguishable from either 9month old or 12-month old untreated rTg4510 (Figure $7 f$ and $\mathrm{g}$ ), and the frontal cortex had significantly lower levels of EB compared to 12-month old untreated rTg4510 mice (Figure $7 \mathrm{~h}$ and i). Similar trends were observed for EB particle count, total area positive and average particle size (Additional file 1: Figure S3) Taken together, this suggests that BBB integrity was maintained and in part restored following tau suppression by DOX. As expected, hippocampal atrophy was also significantly slowed by DOX treatment, as measured by traces used for segmentation from NearCYTE software (Figure 7j). However, 12-month old DOX-treated rTg4510 mice still had significantly lower hippocampal volume than 9month old untreated rTg4510 mice. Altogether, these data suggest that tau suppression can slow and possibly even rescue the progression of $\mathrm{BBB}$ dysfunction in this model of tauopathy.

\section{Tau suppression slows and possibly reverses BBB dysfunction in aged rTg4510 mice}

As expected, total tau levels in DOX-treated mice were significantly decreased in the hippocampus (Figure 8a and b) and frontal cortex (Figure 8c and d) compared to untreated rTg4510 mice. As depicted by the representative images in the hippocampus (Figure $8 \mathrm{~b}$ ) and frontal cortex (Figure 8d), there was a noticeable reduction of the dispersed tau-positive staining in the 12-month old DOX-treated and 9-month old rTg4510 mice compared to 12-month old untreated rTg4510 mice. In fact, the DOX treated mice were statistically indistinguishable from 9-month old untreated $\mathrm{rTg} 4510$ mice. This reduction in dispersed tau staining may be due to a decrease in more soluble tau species which are lowered by DOX, since previous studies showed that insoluble neurofibrillary tangles are not cleared by tau suppression [23]. Hsp27 accumulation was also significantly reduced by tau suppression in both the hippocampus (Figure 8e and $\mathrm{f}$ ) and frontal cortex (Figure $8 \mathrm{~g}$ and $\mathrm{h}$ ), but was still significantly higher than 9-month old untreated rTg4510 mice in the hippocampus (Figure 8e). In addition to slowing the accumulation of the levels of Hsp27, the morphology of cells expressing Hsp27 appears to be slightly altered in both the hippocampus (Figure 8f) and frontal cortex (Figure $8 \mathrm{~h}$ ), suggesting that distinct activation states of astrocytes may also contribute to $\mathrm{BBB}$ disruption.

Confirmation of the reduction of activated astrocytes in DOX-treated rTg4510 mice was verified by GFAP staining, which was recently shown to be rescued by DOX in a separate study [43]. Consistent with Hsp27 staining, GFAP immunoreactivity was significantly lower in the hippocampi of 12-month old DOX-treated rTg4510 mice compared to their untreated counterparts (Figure 9a and b), but still significantly higher than 9-month old untreated rTg4510 mice. In the frontal cortex, GFAP immunoreactivity in 12-month old DOX-treated mice was significantly lower than 12-month old untreated 


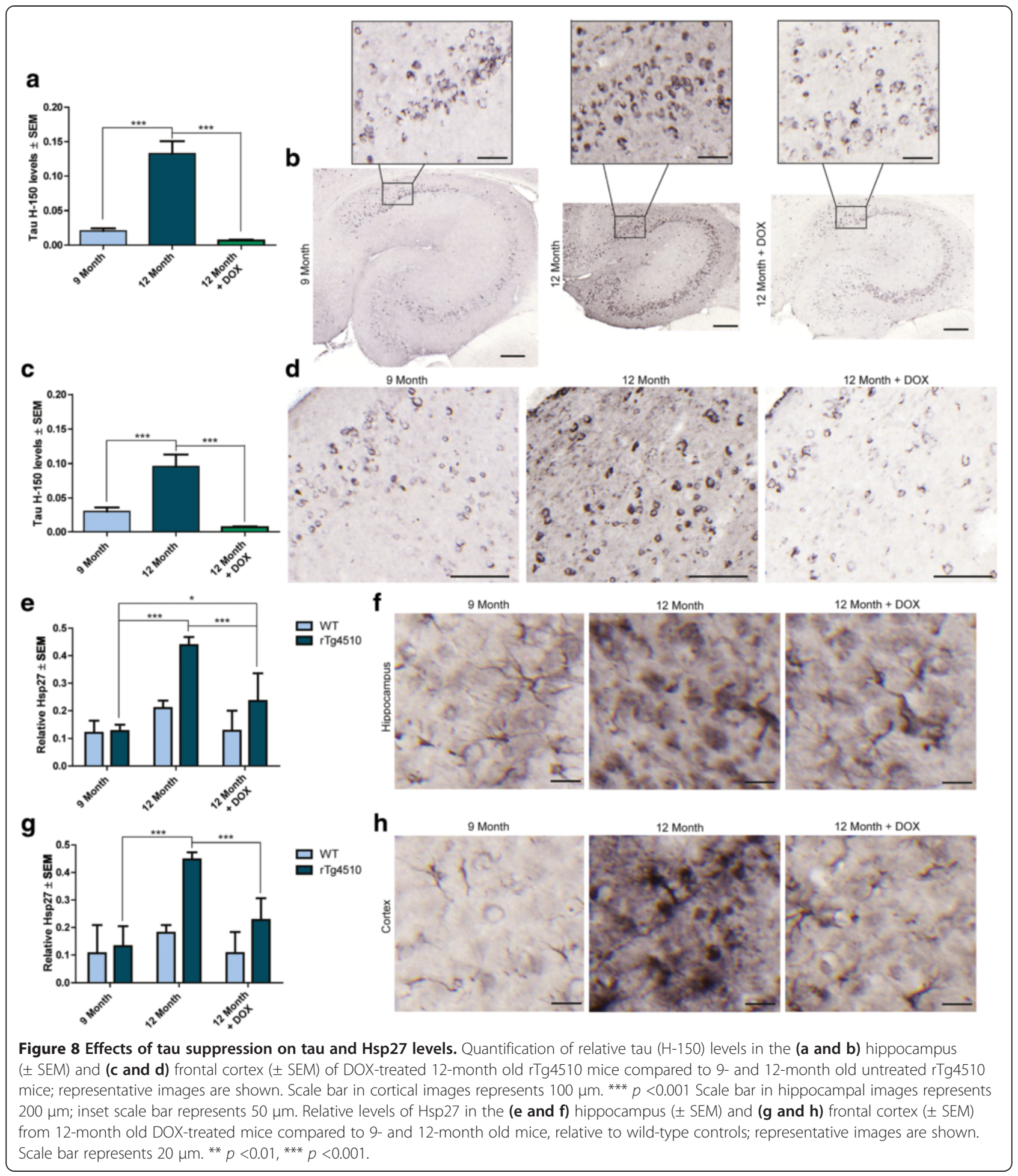

rTg4510 mice, instead resembling 9-month old rTg4510 mice (Figure $9 \mathrm{c}$ and $\mathrm{d}$ ).

T cell lymphocyte and RBC infiltration were also reversed by tau suppression. The RBC counts from 12-month old DOX-treated $\mathrm{rTg} 4510$ mice was significantly lower than 12-month old untreated $\operatorname{rTg} 4510$ mice and were indistinguishable from 9-month old untreated rTg4510 mice (Figure 9e). We also found that $\mathrm{CD}^{+}$(Figure 9f) and $\mathrm{CD}^{+}$(Figure 9g) $\mathrm{T}$ cells were significantly lower in the DOX-treated rTg4510 mice compared to untreated mice. Unlike $\mathrm{CD}^{+}{ }^{+} \mathrm{T}$ cells, $\mathrm{CD} 4^{+} \mathrm{T}$ cells, while reduced, were still significantly higher in 12-month old 


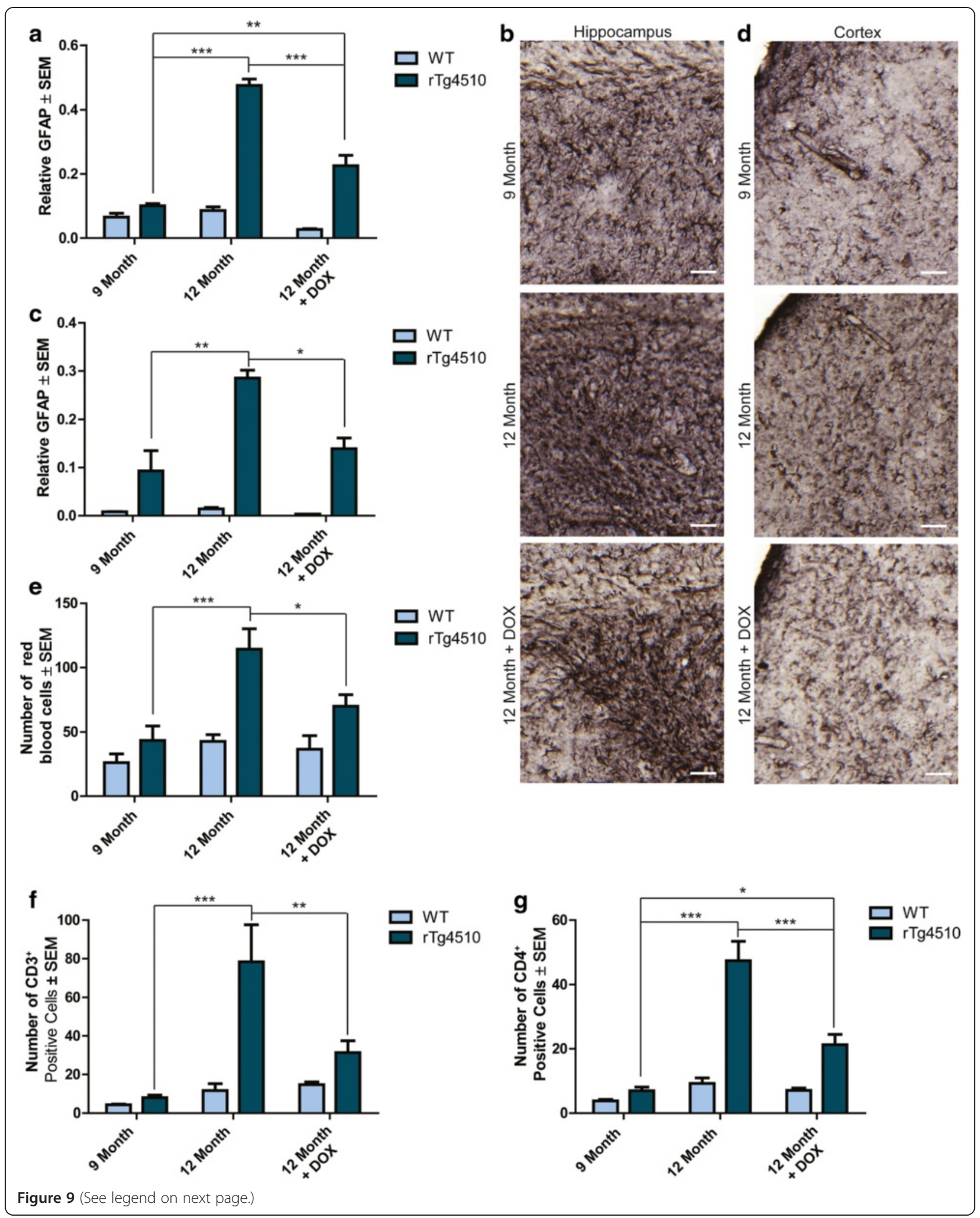


(See figure on previous page.)

Figure 9 Effects of tau suppression on GFAP levels, RBCs and infiltration of T cell lymphocytes. Relative levels of GFAP positive astrocytes in the (a and b) hippocampus and (c and d) frontal cortex of 9-, 12-, and 12-month old + DOX treated rTg4510 and wild-type mice; representative images are shown. Scale bars represent $50 \mu \mathrm{m} .{ }^{*} p<0.05,{ }^{* *} p<0.01,{ }^{* * *} p<0.001$. Number of e RBCs $( \pm$ SEM) counted from H\&E staining of $12-$ month old DOX-treated and 9-and 12-month old untreated $r$ Tg4510 mice relative to the levels of their wild-type littermates. ${ }^{*} p<0.05$, ${ }^{* * *} p<0.001$. Number of $\mathbf{f} \mathrm{CD}^{+}\left( \pm\right.$SEM) and $\mathbf{g} \mathrm{CD}^{+}( \pm$SEM) T cell lymphocytes in 9-, 12- and DOX-treated 12-month old rTg4510 mice compared wild-type controls ${ }^{*} p<0.05$, ** $p<0.01$, *** $p<0.001$.

DOX-treated rTg4510 mice compared to 9-month old rTg4510 mice.

\section{Appearance of perivascular tau in 12-month old rTg4510 mice}

Since the hippocampi of the rTg4510 model develop the most robust and aggressive tau pathology, we examined this area for any apparent differences in the morphology of tau staining. Through this process, we discovered tau immunoreactivity in and around the longitudinal blood vessels of the hippocampus (Figure 10a; additional examples are included in Additional file 1: Figure S4a) $[52,53]$. Quantification of this perivascular tau revealed that it was significantly more abundant in 12-month old rTg4510 mice than in 9-month old rTg4510 mice or 12-month old DOX-treated rTg4510 mice (Figure 10b). Tau was not localized to this region in 12-month old wild-type mice (Figure 10c) or in 6-month old rTg4510 mice (Figure 10d). It only emerged in rTg4510 mice 9 months of age or older (Figure 10e). We found that the accumulation of tau in and around these blood vessels was significant by 12 -months of age (Figure 10f), but was markedly reduced in DOX-treated rTg4510 mice (Figure 10g). Lectin and tau co-staining (Figure 11) revealed that tau was found closely lining the endothelial cells of the blood vessels in the hippocampus in 12-month old rTg4510 mice. This was not found in age-matched WT mice and appeared less robust in 12-month old DOX-treated mice. These findings suggest that tau along these vessels is not within endothelial cells based on the lack of co-localization of tau with lectin staining. We then performed co-localization studies of Hsp27, tau and EB to better define the location of this perivascular tau. Tau was found co-localized with both EB and Hsp27, suggesting that tau and EB were within Hsp27 positive cells along the vasculature (Additional file 1: Figure S4b). Since tau did not appear to co-localize with endothelial cells, and since tau has not been found in neuroglia up to 13 months in the rTg4510 mice by electron microscopy [54], we can conclude that the perivascular tau is likely either within neuronal processes that could contain Hsp27 and EB, or it could be extracellular as both EB and Hsp27 are found outside of cells as well $[55,56]$. Regardless of the localization of this perivascular tau, its emergence coincides much more closely with BBB dysfunction than other pathologies in this model, such as neuronal loss and gliosis. Thus, these findings suggest an important relationship between this perivascular tau pathology and $\mathrm{BBB}$ integrity.

\section{Discussion}

This study is the first to demonstrate that tau derived from neurons can be sufficient to initiate BBB impairment. This dysfunction was found to be concomitant with perivascular tau accumulation, subsequent to the onset of other pathologies found in this mouse model. In fact, the BBB is remarkably stable in the face of robust tau accumulation, neuroinflammation, and neurodegeneration. This is based on our data showing that BBB dysfunction only manifested once vascular tau emerged at 9 months, well after neuronal loss and total tau accumulation begin at 2.5 months and gliosis at 4 months (Figure 12) $[24,43]$. In fact, BBB function in the rTg4510 mice was found to deteriorate at a similar time point as the emergence of perivascular tau along the hippocampal vessels (Figure 10f, g and h). The accumulation of tau in the forebrain and hippocampus [24] is the nexus which leads to BBB dysfunction in the rTg4510 model, either directly or indirectly.

Tau-induced neuronal loss and inflammation are apparent much earlier in the rTg4510 model than BBB dysfunction. But while inflammation in particular is a known regulator of $\mathrm{BBB}$ stability [57], gliosis emerges at nearly the same time and place as tau aggregates begin to appear in the rTg4510 model, both of which occur at a much younger age relative to the emergence of $\mathrm{BBB}$ pathology. This suggests that there may be a threshold that tau-induced inflammation and/or neurodegeneration must surpass to induce BBB permeability at 9 months in this model. Alternatively, it could be a distinct pathology that arises, such as the accumulation of perivascular tau, or a combination of these factors. Interestingly, $\mathrm{BBB}$ damage in this model appeared greatest in areas such as CA3 and the surface of the cortex, adjacent to the areas that have the most robust neuronal loss and gliosis such as CA1 and frontal midcortical layers. In fact, BBB damage was highest near the ventricles and the meninges, the same areas that show signs of BBB leakage in normal aging [37]. In this way, the BBB damage in the rTg4510 brain is similar to that in the normal aging brain with regard to location of initial insult; however this pathology is greatly 


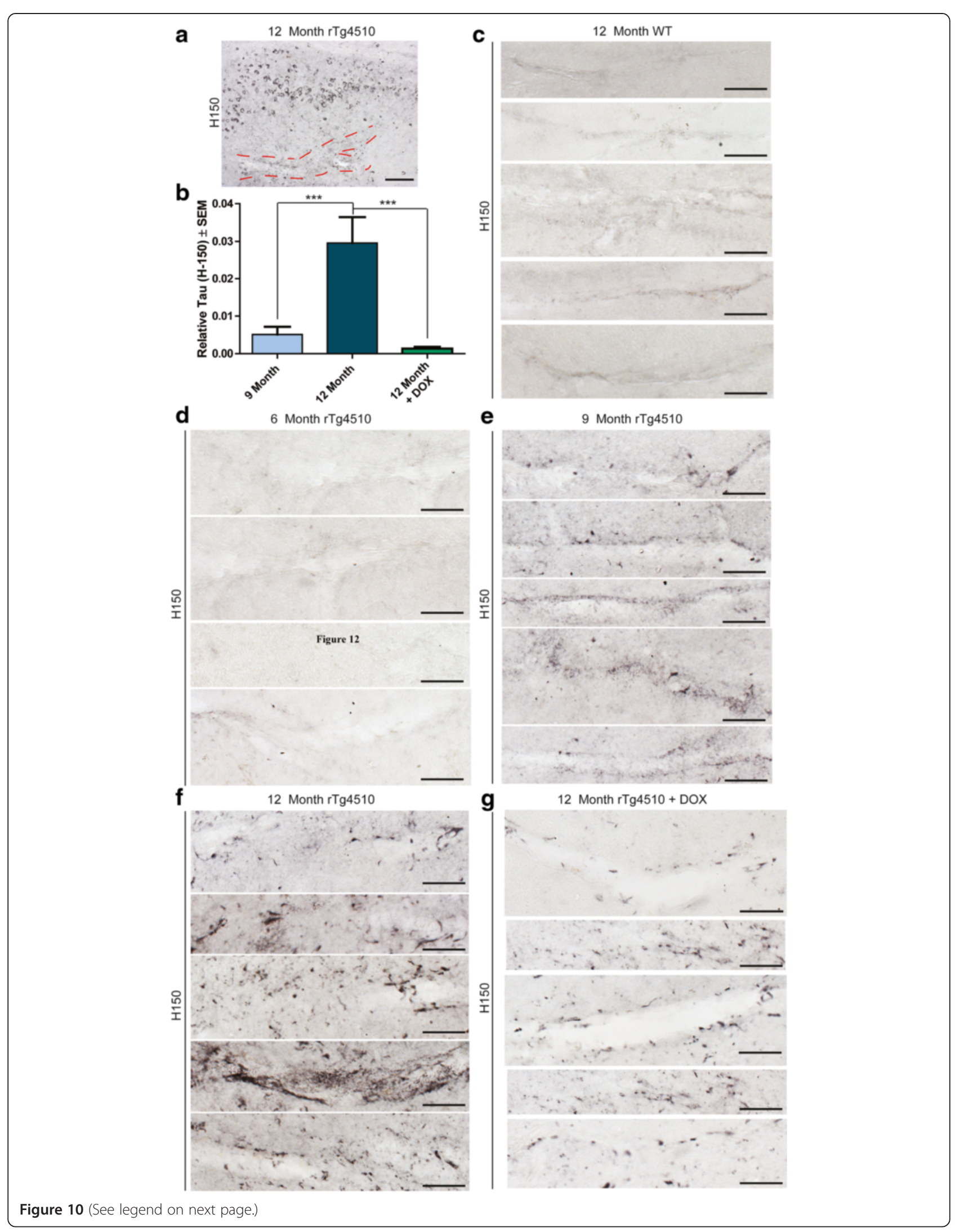


(See figure on previous page.)

Figure 10 Tau accumulates along hippocampal blood vessels in 12-month old rT4510 mice. 20x magnification image of the a hippocampus of a 12-month old rTg4510 mouse stained with tau ( $\mathrm{H}-150)$ to show the region of perivascular tau accumulation. Scale bar represents $100 \mu \mathrm{m}$. Relative levels of $\mathbf{b}$ tau $(\mathrm{H}-150)$ ( \pm SEM) were measured in and around the longitudinal hippocampal blood vessels in 9- and 12-month old and 12-month old rTg4510 mice treated with DOX. ${ }^{* * *} p<0.001$. Representative images of tau (H-150) stained tissue from a c 12-month wild-type mouse and rTg4510 mice at d 6, e 9, and f 12 months of age, and $\mathbf{g} 12$-month old rTg4510 mice DOX-treated mice are shown. Scale bars represent 50 mm.

accelerated, suggesting that the pathologies caused by tau accumulation somehow interact with normal aging pathologies to cause this BBB damage. While the precise mechanism contributing to BBB dysfunction in these mice remains unknown, it is clear that the brain is highly resistant to $\mathrm{BBB}$ damage in the face of major pathological insults, and only results through a complex pathogenic cascade much later in the rTg4510 brain.

Still, the specific mechanism by which tau causes BBB dysfunction remains unclear. Perhaps tau aggregation works in a way that is similar to vascular $A ß$, by decreasing glucose transporters [58] stimulating reactive oxygen species [59], and increasing inflammatory molecules [59-61]. In fact, tau accumulation is associated with increased inflammation leading to stimulation of TNF- $\alpha$ and MCP-1, and both of these have been implicated in BBB dysfunction [21,62]. Moreover, the tau accumulating along the vasculature in the $\mathrm{rTg} 4510$ mice could be extracellular, perhaps suggesting some type of physical damage to the endothelial cells. There is evidence that tau transgenic models do produce extracellular tau $[63,64]$ and recent work suggests that tau can spread in a prion-like manner in these same mouse models [65-67], further suggesting the potential for a pathological role of extracellular tau. Tau has also been shown to accumulate into annular protofibrils, which may be able to puncture membranes [68], suggesting perhaps another way for tau to damage the BBB. It is also possible that tau is able to damage the $\mathrm{BBB}$ from within cells. In human AD brain, it was recently demonstrated that tau is not only found near the vasculature [14], but tau oligomers specifically co-localized with endothelial cells within the blood vessels, suggesting that tau was either extracellular or within pericytes or endothelial cells [69]. However our data would suggest that this is not the case in the rTg4510 model, since tau did not strongly co-localize with lectin staining. Another possibility is that neuronal tau accumulation triggers astrocytosis, causing these cells to detach from tight junctions. Also, while likely not relevant to this model because there is no pathological evidence of glial tau in the rTg4510 mice, astrocytic tau has been shown to compromise the BBB by damaging endfeet [18]. Still another mechanism is that tau within endothelial cells themselves can become aberrantly phosphorylated, leading to BBB disruption $[54,70,71]$.

Interestingly, vascular tau is also found in $\mathrm{AD}$ cases with CAA [72-74], but this has typically been hypothesized to be downstream of Aß-triggered $\mathrm{BBB}$ dysfunction, rather than a causal pathology. There is also evidence that mouse models expressing both mutant amyloid precursor protein or Presenilin 1 have some tau present along the vasculature $[13,75]$, but this was speculated to be a consequence of $A ß$ deposition rather than a pathophysiological function of tau. Thus, while the prevailing dogma in $\mathrm{AD}$ is that $\mathrm{A} ß$ triggers the $\mathrm{BBB}$ dysfunction, our findings clearly show that tau alone is capable initiating impaired BBB stability independent of Aß.

Perivascular tau is also present in progressive supranuclear palsy (PSP) and corticobasal degeneration (CBD), suggesting that $\mathrm{AD}$ is not the only tauopathy to show a BBB defect [76,77]. In contrast to PSP and CBD, AD tau tangles contain exon $10(+)$ and exon $10(-)$ tau species while tangles from PSP and CBD are exclusively exon 10 (+). Both PSP and AD have neuritic plaques, but only AD has neuropil threads. Moreover, tau pathology in the AD brain originates in the entorhinal cortex and hippocampus, eventually spreading throughout the forebrain, but in PSP tau pathology is restricted to the basal ganglia, brainstem, substantia nigra, and subthalamic nucleus [78,79], and in CBD it is restricted to the cerebral cortex [79]. Perhaps most distinct is that tau in PSP and CBD brain accumulates within astrocytes [76], while AD brain shows no signs of neuroglial tau pathology. Despite these distinct pathologies, like AD, there is clear evidence for BBB damage in PSP that has been associated with decreased P-glycoprotein, a transporter found in endothelial cells within the BBB $[15,77]$. Unlike AD where the perivascular tau is thought to arise from neurons, perivascular tau in PSP was attributed to tau derived from tangle bearing thorn-shaped glial cells [80] and perivascular tau in CBD is most closely associated with astrocytic tau [81]. But, despite different origins, perivascular tau accumulates in each of these diseases, providing further support for a role of tau pathology in BBB damage. Thus, the rTg4510 mice likely most accurately model the BBB defect caused by tau in the AD brain since the tau is neuronally derived and the location of the pathology. However, since the accumulation 


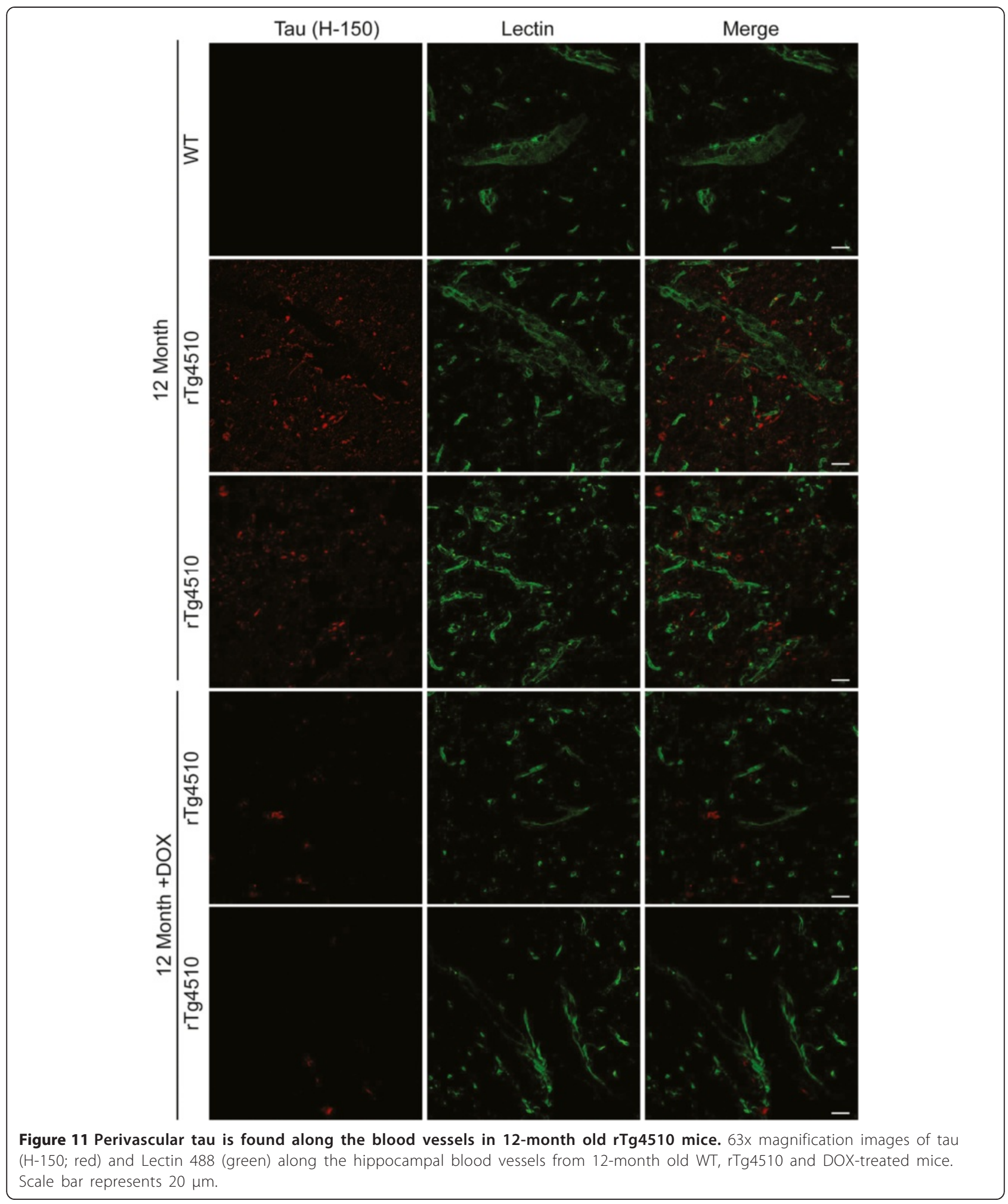

of perivascular tau is common in each disease, it is possible that the $\mathrm{r} \operatorname{Tg} 4510$ mice, which also have perivascular tau accumulation, could define the role of this particular tau pathology in BBB function.

\section{Conclusion}

In summary, we show that tau derived from neurons causes a progressive BBB dysfunction that is most closely correlated with the emergence of perivascular tau, rather 


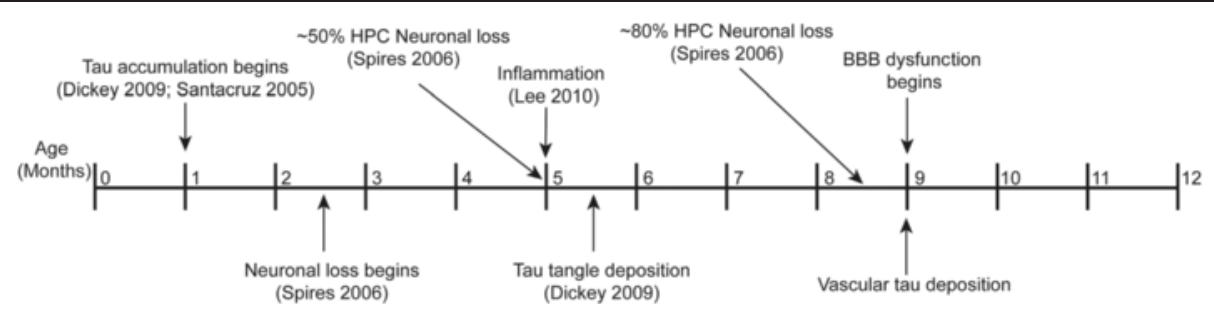

Figure 12 BBB breakdown correlates best with perivascular tau levels. Representative schematic depicting the timeline of progressive pathologies found in rTg4510 mice including tau accumulation, neuronal loss, tau tangle deposition, inflammation, appearance of perivascular tau, and initiation of increased BBB permeability. Tau accumulation begins at a very young age, before one month, followed by regional neuronal loss. A few months after tau tangles start to deposit just after signs of inflammation are noticeable. Neuron loss continues to get more severe with age and by 9 months vascular tau is detectable in the hippocampus, concomitant with the start of increased BBB permeability.

than the robust neuronal loss and neuroinflammation that occurs much earlier in the pathogenic cascade of the rTg4510 model. Importantly, reducing tau levels recovered the $\mathrm{BBB}$ defect, demonstrating its remarkable resiliency, even in the face of dramatic degeneration and inflammation. Thus, the threshold for BBB integrity is extremely high in the mouse brain and as a result BBB damage appears to be the last chip to fall in the neurotoxic sequelae of this model. Furthermore, this BBB defect in the rTg4510 mouse model can now be used to more adequately model the pharmacokinetic profile of promising pre-clinical therapies to treat tauopathies, since $\mathrm{BBB}$ dysfunction is found in $\mathrm{AD}$, traumatic brain injury (TBI) and other tauopathies. Since peripheral infiltration of inflammatory components into the brain is thought to contribute to the late stage sequelae in $\mathrm{AD}$ and other tauopathies [82-85], our findings suggest that even late stage interventions targeting tau could help maintain $\mathrm{BBB}$ integrity and reduce the vascular contributions to cognitive impairment and dementia that occur in these diseases. Overall, this work demonstrates that tau accumulation can damage the BBB to the point that whole peripheral cells can now enter the brain, perhaps initiating a secondary disease cascade involving the peripheral immune system. But this process is late in the disease process and can be stopped if tau levels are reduced.

\section{Additional file}

Additional file 1: Figure S1. Evans blue fluorescence in subregions of the hippocampus. Quantification of EB fluorescence in the CA1, CA3, and dentate gyrus regions of the hippocmapus from 12-month old rTg4510 and wild-type mice. ${ }^{* *} p<0.001$. Figure S2. Hippocampal atrophy with aging in the rTg4510 mouse model. Quantification of relative hippocampal volume at 6-, 9- and 12-months. ${ }^{*} p<0.05,{ }^{* * *} p<0.001$. Figure S3. Additional Evans blue (EB) measurements. Average count of independent EB positive spots per a hippocampus and $\mathbf{b}$ frontal cortex. ${ }^{*} p<0.05,{ }^{* *} p<0.01$. Total $E B$ positivity (pixels) in each $\mathbf{c}$ hippocampus and $\mathbf{d}$ frontal cortex. ${ }^{* * *} \mathrm{p}<0.001$. Average size of independent EB positive areas per e hippocampus and f frontal cortex. ${ }^{* *} p<0.001$. Figure S4. Perivascular tau is found along the hippocampal blood vessels. a Total tau $(\mathrm{H}-150)$ reactivity in the hippocampus of 12-month old rTg4510 mice. Images taken at 20x magnification. Scale bar represents $100 \mu \mathrm{m}$. b Representative images of hippocampal blood vessels from 12-month old wild-type, rTg4510 and rTg4510 + DOX stained for Hsp27, tau (v-20), and Evans blue. Images taken at 60x magnification. Scale bar represents $50 \mu \mathrm{m}$.

\section{Abbreviations}

AB: Amyloid beta; AD: Alzheimer's disease; BBB: Blood-brain barrier; CAA: Cerebral amyloid angiopathy; CBD: Corticobasal degeneration; DOX: Doxycycline; EB: Evans blue; GFAP: Glial fibrillary acidic protein; H\&E: Hematoxylin and eosin; Hsp27: Heat shock protein 27 kDa; NFT: Neurofibrillary tangle; PSP: Progressive supranuclear palsy; RBC: Red blood cell; TBI: Traumatic brain injury.

\section{Competing interests}

The authors declare that they have no competing interest.

\section{Authors' contributions}

LJB, helped plan the study and with help from others executed the experiments, data collection and analysis and drafted the manuscript; HDF, executed the DOX treatment, tissue processing, and data collection; BZ and BAN, maintained the mouse colony and genotyping of the mice used in this experiment, SB, YL LDH and FZ helped with the processing of the tissue for the aging study and staining; JJS, reviewed and edited the manuscript; MBS, contributed guidance and reagents for the T cell and GFAP studies; CAD conceived of the study, designed and oversaw coordination of experiments and helped draft the manuscript. All authors read and approved the final manuscript.

\section{Acknowledgements}

This material is the result of work supported with resources and the use of facilities at the James A. Haley Veterans' Hospital under merit review award BX001637. The contents of this publication do not represent the views of the Department of Veterans Affairs or the United States Government. This work was also supported by the National Institutes of Health/National Institute of Neurological Disorders and Stroke R01 NS073899. We would like to thank Dr. Beyong "Jake" Cha and the USF Lisa Muma Weitz Imaging Core for the use of the Leica SP2 confocal microscope.

\section{Author details}

'Department of Molecular Medicine, University of South Florida, Byrd Alzheimer's Institute, 4001 E. Fletcher Ave MDC 36, Tampa, FL 33613, USA. 2James A. Haley Veteran's Hospital, 13000 Bruce B. Downs Blvd., Tampa, FL 33612, USA. ${ }^{3}$ Department of Pharmaceutical Science, University of South Florida, Byrd Alzheimer's Institute, 4001 E. Fletcher Ave University of South Florida, Tampa, FL 33613, USA.

Received: 6 January 2015 Accepted: 12 January 2015

Published online: 31 January 2015 


\section{References}

1. Broadwell RD, Salcman M (1981) Expanding the definition of the blood-brain barrier to protein. Proc Natl Acad Sci U S A 78(12):7820-7824

2. Wenkel H, Streilein JW, Young MJ (2000) Systemic immune deviation in the brain that does not depend on the integrity of the blood-brain barrier. J Immunol 164(10):5125-5131

3. Mooradian AD (1988) Effect of aging on the blood-brain barrier. Neurobiol Aging 9(1):31-39

4. Marques F, Sousa JC, Sousa N, Palha JA (2013) Blood-brain-barriers in aging and in Alzheimer's disease. Mol Neurodegener 8:38, doi:10.1186/1750-1326-8-38

5. Sengillo JD, Winkler EA, Walker CT, Sullivan JS, Johnson M, Zlokovic BV (2013) Deficiency in mural vascular cells coincides with blood-brain barrier disruption in Alzheimer's disease. Brain Pathol 23(3):303-310, doi:10.1111/bpa.12004

6. Viggars AP, Wharton SB, Simpson JE, Matthews FE, Brayne C, Savva GM, Garwood C, Drew D, Shaw PJ, Ince PG (2011) Alterations in the blood brain barrier in ageing cerebral cortex in relationship to Alzheimer-type pathology: a study in the MRC-CFAS population neuropathology cohort. Neurosci Lett 505(1):25-30, doi:10.1016/j.neulet.2011.09.049

7. Bowman GL, Kaye JA, Moore M, Waichunas D, Carlson NE, Quinn JF (2007) Blood-brain barrier impairment in Alzheimer disease: stability and functional significance. Neurology 68(21):1809-1814, doi:10.1212/01. wnl.0000262031.18018.1a

8. Desai BS, Monahan AJ, Carvey PM, Hendey B (2007) Blood-brain barrier pathology in Alzheimer's and Parkinson's disease: implications for drug therapy. Cell Transplant 16(3):285-299

9. Sharma HS, Castellani RJ, Smith MA, Sharma A (2012) The blood-brain barrier in Alzheimer's disease: novel therapeutic targets and nanodrug delivery. Int Rev Neurobiol 102:47-90, doi:10.1016/B978-0-12-386986-9.00003-X

10. Zlokovic BV (2008) The blood-brain barrier in health and chronic neurodegenerative disorders. Neuron 57(2):178-201, doi:10.1016/j.neuron.2008.01.003

11. Erickson MA, Banks WA (2013) Blood-brain barrier dysfunction as a cause and consequence of Alzheimer's disease. J Cereb Blood Flow Metab 33(10):1500-1513, doi:10.1038/jcbfm.2013.135

12. Oshima K, Uchikado H, Dickson DW (2008) Perivascular neuritic dystrophy associated with cerebral amyloid angiopathy in Alzheimer's disease. Int J Clin Exp Pathol 1(5):403-408

13. Wilcock DM, Lewis MR, Van Nostrand WE, Davis J, Previti ML, Gharkholonarehe N, Vitek MP, Colton CA (2008) Progression of amyloid pathology to Alzheimer's disease pathology in an amyloid precursor protein transgenic mouse model by removal of nitric oxide synthase 2. J Neurosci 28(7):1537-1545, doi:10.1523/JNEUROSCI. 5066-07.2008

14. Vidal R, Calero M, Piccardo P, Farlow MR, Unverzagt FW, Mendez E, Jimenez-Huete A, Beavis R, Gallo G, Gomez-Tortosa E, Ghiso J, Hyman BT, Frangione B, Ghetti B (2000) Senile dementia associated with amyloid beta protein angiopathy and tau perivascular pathology but not neuritic plaques in patients homozygous for the APOE-epsilon4 allele. Acta Neuropathol 100(1):1-12

15. Bartels AL, Willemsen AT, Kortekaas R, de Jong BM, de Vries R, de Klerk O, van Oostrom JC, Portman A, Leenders KL (2008) Decreased blood-brain barrier P-glycoprotein function in the progression of Parkinson's disease, PSP and MSA. J Neural Transm 115(7):1001-1009, doi:10.1007/s00702-008-0030-y

16. de Vries HE, Kuiper J, de Boer AG, Van Berkel TJ, Breimer DD (1997) The blood-brain barrier in neuroinflammatory diseases. Pharmacol Rev 49(2):143-155

17. Garbuzova-Davis S, Hernandez-Ontiveros DG, Rodrigues MC, Haller E, Frisina-Deyo A, Mirtyl S, Sallot S, Saporta S, Borlongan CV, Sanberg PR (2012) Impaired blood-brain/spinal cord barrier in ALS patients. Brain Res 1469:114-128, doi:10.1016/j.brainres.2012.05.056

18. Forman MS, Lal D, Zhang B, Dabir DV, Swanson E, Lee VM, Trojanowski JQ (2005) Transgenic mouse model of tau pathology in astrocytes leading to nervous system degeneration. J Neurosci 25(14):3539-3550, doi:10.1523/ JNEUROSCl. 0081-05.2005

19. Jaworski T, Dewachter I, Lechat B, Croes S, Termont A, Demedts D, Borghgraef P, Devijver H, Filipkowski RK, Kaczmarek L, Kugler S, Van Leuven F (2009) AAV-tau mediates pyramidal neurodegeneration by cell-cycle re-entry without neurofibrillary tangle formation in wild-type mice. PLoS ONE 4(10):e7280, doi:10.1371/journal.pone.0007280

20. Jaworki T, Lechat B, Demedts D, Gielis L, Devijver H, Borghgraef P, Duimel H, Verheyen F, Kugler S, Van Leuven F (2011) Dendritic degeneration, neurovascular defects, and inflammation precede neuronal loss in a mouse model for tau-mediated neurodegeneration. Am J Pathol 179(4):2001-2015, doi:10.1016/j.ajpath.2011.06.025

21. Kovac A, Zilkova M, Deli MA, Zilka N, Novak M (2009) Human truncated tau is using a different mechanism from amyloid-beta to damage the blood-brain barrier. J Alzheimers Dis 18(4):897-906, doi:10.3233/JAD-2009-1197

22. Dickey C, Kraft C, Jinwal U, Koren J, Johnson A, Anderson L, Lebson L, Lee D, Dickson D, de Silva R, Binder LI, Morgan D, Lewis J (2009) Aging analysis reveals slowed tau turnover and enhanced stress response in a mouse model of tauopathy. Am J Pathol 174(1):228-238, doi:10.2353/ ajpath.2009.080764

23. Santacruz K, Lewis J, Spires T, Paulson J, Kotilinek L, Ingelsson M, Guimaraes A, DeTure M, Ramsden M, McGowan E, Forster C, Yue M, Orne J, Janus C, Mariash A, Kuskowski M, Hyman B, Hutton M, Ashe KH (2005) Tau suppression in a neurodegenerative mouse model improves memory function. Science 309(5733):476-481

24. Spires TL, Orne JD, SantaCruz K, Pitstick R, Carlson GA, Ashe KH, Hyman BT (2006) Region-specific dissociation of neuronal loss and neurofibrillary pathology in a mouse model of tauopathy. Am J Pathol 168(5):1598-1607, doi:168/5/1598

25. Blair LJ, Nordhues BA, Hill SE, Scaglione KM, O'Leary JC 3rd, Fontaine SN, Breydo L, Zhang B, Li P, Wang L, Cotman C, Paulson HL, Muschol M, Uversky VN, Klengel T, Binder EB, Kayed R, Golde TE, Berchtold N, Dickey CA (2013) Accelerated neurodegeneration through chaperone-mediated oligomerization of tau. J Clin Invest 123(10):4158-4169, doi:10.1172/JCl69003

26. Sahara N, DeTure M, Ren Y, Ebrahim AS, Kang D, Knight J, Volbracht C, Pedersen JT, Dickson DW, Yen SH, Lewis J (2013) Characteristics of TBS-extractable hyperphosphorylated tau species: aggregation intermediates in rTg4510 mouse brain. J Alzheimers Dis 33(1):249-263, doi:10.3233/JAD-2012-121093

27. Sahara N, Ren Y, Ward S, Binder LI, Suhara T, Higuchi M (2014) Tau oligomers as potential targets for early diagnosis of tauopathy. J Alzheimers Dis 40:S91-S96, doi:10.3233/JAD-132429

28. Rudd PA, Bastien-Hamel LE, von Messling V (2010) Acute canine distemper encephalitis is associated with rapid neuronal loss and local immune activation. J Gen Virol 91(Pt 4):980-989, doi:10.1099/vir. 0.017780-0

29. Tetrault S, Chever O, Sik A, Amzica F (2008) Opening of the blood-brain barrier during isoflurane anaesthesia. Eur J Neurosci 28(7):1330-1341, doi:10.1111/j.1460-9568.2008.06443.x

30. Gordon MN, Schreier WA, Ou X, Holcomb LA, Morgan DG (1997) Exaggerated astrocyte reactivity after nigrostriatal deafferentation in the aged rat. J Comp Neurol 388(1):106-119

31. Abisambra JF, Blair LJ, Hill SE, Jones JR, Kraft C, Rogers J, Koren J 3rd, Jinwal UK, Lawson L, Johnson AG, Wilcock D, O'Leary JC, Jansen-West K, Muschol M, Golde TE, Weeber EJ, Banko J, Dickey CA (2010) Phosphorylation dynamics regulate Hsp27-mediated rescue of neuronal plasticity deficits in tau transgenic mice. J Neurosci 30(46):15374-15382, doi:10.1523/JNEUROSCI. 3155-10.2010

32. Fischer AH, Jacobson KA, Rose J, Zeller R (2008) Hematoxylin and eosin staining of tissue and cell sections. CSH Protocols 2008:pdb prot4986, doi:10.1101/pdb.prot4986

33. Carty N, Lee D, Dickey C, Ceballos-Diaz C, Jansen-West K, Golde TE, Gordon MN, Morgan D, Nash K (2010) Convection-enhanced delivery and systemic mannitol increase gene product distribution of AAV vectors 5, 8, and 9 and increase gene product in the adult mouse brain. J Neurosci Methods 194(1):144-153, doi:10.1016/j.jneumeth.2010.10.010

34. Corbitt N, Kimura S, Isse K, Specht S, Chedwick L, Rosborough BR, Lunz JG, Murase N, Yokota S, Demetris AJ (2013) Gut bacteria drive Kupffer cell expansion via MAMP-mediated ICAM-1 induction on sinusoidal endothelium and influence preservation-reperfusion injury after orthotopic liver transplantation. Am J Pathol 182(1):180-191, doi:10.1016/j.ajpath.2012.09.010

35. Pluta R, Januszewski S, Jablonski M, Ulamek M (2010) Factors in creepy delayed neuronal death in hippocampus following brain ischemia-reperfusion injury with long-term survival. Acta neurochirurgica Suppl 106:37-41, doi:10.1007/978-3-211-98811-4_5

36. Ueno M, Sakamoto $H$, Tomimoto $H$, Akiguchi I, Onodera M, Huang CL, Kanenishi K (2004) Blood-brain barrier is impaired in the hippocampus of young adult spontaneously hypertensive rats. Acta Neuropathol 107(6):532-538, doi:10.1007/s00401-004-0845-z

37. Ueno M, Akiguchi I, Hosokawa M, Kotani H, Kanenishi K, Sakamoto H (2000) Blood-brain barrier permeability in the periventricular areas of the normal mouse brain. Acta Neuropathol 99(4):385-392 
38. Ramsden M, Kotilinek L, Forster C, Paulson J, McGowan E, SantaCruz K, Guimaraes A, Yue M, Lewis J, Carlson G, Hutton M, Ashe KH (2005) Age-dependent neurofibrillary tangle formation, neuron loss, and memory impairment in a mouse model of human tauopathy (P301L). J Neurosci 25(46):10637-10647, doi:10.1523/JNEUROSCI. 3279-05.2005

39. Saria A, Lundberg JM (1983) Evans blue fluorescence: quantitative and morphological evaluation of vascular permeability in animal tissues. J Neurosci Methods 8(1):41-49

40. Vaz R, Sarmento A, Borges N, Cruz C, Azevedo T (1998) Experimental traumatic cerebral contusion: morphological study of brain microvessels and characterization of the oedema. Acta Neurochir 140(1):76-81

41. Yen LF, Wei VC, Kuo EY, Lai TW (2013) Distinct patterns of cerebral extravasation by Evans blue and sodium fluorescein in rats. PLoS ONE 8(7): e68595, doi:10.1371/journal.pone.0068595

42. Berger Z, Roder H, Hanna A, Carlson A, Rangachari V, Yue M, Wszolek Z, Ashe K, Knight J, Dickson D, Andorfer C, Rosenberry TL, Lewis J, Hutton M, Janus C (2007) Accumulation of pathological tau species and memory loss in a conditional model of tauopathy. J Neurosci 27(14):3650-3662, doi:10.1523/JNEUROSCI. 0587-07.2007

43. Wes PD, Easton A, Corradi J, Barten DM, Devidze N, DeCarr LB, Truong A, He A, Barrezueta NX, Polson C, Bourin C, Flynn ME, Keenan S, Lidge R, Meredith J, Natale J, Sankaranarayanan S, Cadelina GW, Albright CF, Cacace AM (2014) Tau overexpression impacts a neuroinflammation gene expression network perturbed in Alzheimer's disease. PLoS ONE 9(8):e106050, doi:10.1371/journal. pone.0106050

44. Abbott NJ, Ronnback L, Hansson E (2006) Astrocyte-endothelial interactions at the blood-brain barrier. Nat Rev Neurosci 7(1):41-53, doi:10.1038/nrn1824

45. Koren J 3rd, Jinwal UK, Lee DC, Jones JR, Shults CL, Johnson AG, Anderson $\sqcup$, Dickey CA (2009) Chaperone signalling complexes in Alzheimer's disease. J Cell Mol Med 13(4):619-630

46. Imura T, Shimohama S, Sato M, Nishikawa H, Madono K, Akaike A, Kimura J (1999) Differential expression of small heat shock proteins in reactive astrocytes after focal ischemia: possible role of beta-adrenergic receptor. J Neurosci 19(22):9768-9779

47. Piotrowicz RS, Hickey E, Levin EG (1998) Heat shock protein 27 kDa expression and phosphorylation regulates endothelial cell migration. Faseb J 12(14):1481-1490

48. Leszczynski D, Joenvaara S, Reivinen J, Kuokka R (2002) Non-thermal activation of the hsp27/p38MAPK stress pathway by mobile phone radiation in human endothelial cells: molecular mechanism for cancer- and blood-brain barrier-related effects. Differentiation 70(2-3):120-129, doi:10.1046/j.14320436.2002.700207.x

49. San Jose I, Garcia-Atares N, Pelaez B, Cabo R, Esteban I, Vega JA, Represa J (2001) Reduction of glial fibrillary acidic protein-immunoreactive astrocytes in some brain areas of old hairless rhino-j mice (hr-rh-j). Neurosci Lett 309(2):81-84

50. Schmidt-Kastner R, Wietasch K, Weigel H, Eysel UT (1993) Immunohistochemical staining for glial fibrillary acidic protein (GFAP) after deafferentation or ischemic infarction in rat visual system: features of reactive and damaged astrocytes. Int J Dev Neurosci 11(2):157-174

51. Graesser D, Solowiej A, Bruckner M, Osterweil E, Juedes A, Davis S, Ruddle $\mathrm{NH}$, Engelhardt B, Madri JA (2002) Altered vascular permeability and early onset of experimental autoimmune encephalomyelitis in PECAM-1-deficient mice. J Clin Invest 109(3):383-392, doi:10.1172/JCl13595

52. Choi JJ, Wang S, Tung YS, Morrison B 3rd, Konofagou EE (2010) Molecules of various pharmacologically-relevant sizes can cross the ultrasound-induced blood-brain barrier opening in vivo. Ultrasound Med Biol 36(1):58-67, doi:10.1016/j.ultrasmedbio.2009.08.006

53. Pathak AP, Kim E, Zhang J, Jones MV (2011) Three-dimensional imaging of the mouse neurovasculature with magnetic resonance microscopy. PLoS ONE 6(7):e22643, doi:10.1371/journal.pone.0022643

54. Ludvigson AE, Luebke Jl, Lewis J, Peters A (2011) Structural abnormalities in the cortex of the rTg4510 mouse model of tauopathy: a light and electron microscopy study. Brain Struct Funct 216(1):31-42, doi:10.1007/s00429-010-0295-4

55. Seiffert E, Dreier JP, Ivens S, Bechmann I, Tomkins O, Heinemann U, Friedman A (2004) Lasting blood-brain barrier disruption induces epileptic focus in the rat somatosensory cortex. J Neurosci 24(36):7829-7836, doi:10.1523/JNEUROSCI. 1751-04.2004

56. Thuringer D, Jego G, Wettstein G, Terrier O, Cronier L, Yousfi N, Hebrard S, Bouchot A, Hazoume A, Joly AL, Gleave M, Rosa-Calatrava M, Solary E, Garrido C (2013) Extracellular HSP27 mediates angiogenesis through Toll-like receptor 3. Faseb J 27(10):4169-4183, doi:10.1096/fj.12-226977

57. de Vries HE, Kooij G, Frenkel D, Georgopoulos S, Monsonego A, Janigro D (2012) Inflammatory events at blood-brain barrier in neuroinflammatory and neurodegenerative disorders: implications for clinical disease. Epilepsia 53(Suppl 6):45-52, doi:10.1111/j.1528-1167.2012.03702.x

58. Merlini M, Meyer EP, Ulmann-Schuler A, Nitsch RM (2011) Vascular beta-amyloid and early astrocyte alterations impair cerebrovascular function and cerebral metabolism in transgenic arcAbeta mice. Acta Neuropathol 122(3):293-311, doi:10.1007/s00401-011-0834-y

59. Carrano A, Hoozemans JJ, van der Vies SM, Rozemuller AJ, van Horssen J, de Vries HE (2011) Amyloid Beta induces oxidative stress-mediated blood-brain barrier changes in capillary amyloid angiopathy. Antioxid Redox Signal 15(5):1167-1178, doi:10.1089/ars.2011.3895

60. Fiala M, Zhang L, Gan X, Sherry B, Taub D, Graves MC, Hama S, Way D, Weinand M, Witte M, Lorton D, Kuo YM, Roher AE (1998) Amyloid-beta induces chemokine secretion and monocyte migration across a human blood-brain barrier model. Mol Med 4(7):480-489

61. Schreibelt G, Kooij G, Reijerkerk A, van Doorn R, Gringhuis SI, van der Pol S, Weksler BB, Romero IA, Couraud PO, Piontek J, Blasig IE, Dijkstra CD, Ronken E, de Vries HE (2007) Reactive oxygen species alter brain endothelial tight junction dynamics via RhoA, PI3 kinase, and PKB signaling. Faseb J 21(13):3666-3676, doi:10.1096/fj.07-8329com

62. Lee DC, Rizer J, Selenica ML, Reid P, Kraft C, Johnson A, Blair L, Gordon MN, Dickey CA, Morgan D (2010) LPS- induced inflammation exacerbates phospho-tau pathology in rTg4510 mice. J Neuroinflammation 7:56, doi:10.1186/1742-2094-7-56

63. Yamada K, Cirrito JR, Stewart FR, Jiang H, Finn MB, Holmes BB, Binder LI, Mandelkow EM, Diamond MI, Lee VM, Holtzman DM (2011) In vivo microdialysis reveals age-dependent decrease of brain interstitial fluid tau levels in P301S human tau transgenic mice. J Neurosci 31(37):13110-13117, doi:10.1523/JNEUROSCI. 2569-11.2011

64. Yamada K, Holth JK, Liao F, Stewart FR, Mahan TE, Jiang H, Cirrito JR, Patel TK, Hochgrafe K, Mandelkow EM, Holtzman DM (2014) Neuronal activity regulates extracellular tau in vivo. J Exp Med 211(3):387-393, doi:10.1084/ jem.20131685

65. Clavaguera F, Bolmont T, Crowther RA, Abramowski D, Frank S, Probst A, Fraser G, Stalder AK, Beibel M, Staufenbiel M, Jucker M, Goedert M, Tolnay M (2009) Transmission and spreading of tauopathy in transgenic mouse brain. Nat Cell Biol 11(7):909-913, doi:10.1038/ncb1901

66. Hall GF, Patuto BA (2012) Is tau ready for admission to the prion club? Prion 6(3):223-233, doi:10.4161/pri.19912

67. Iba M, Guo JL, McBride JD, Zhang B, Trojanowski JQ, Lee VM (2013) Synthetic tau fibrils mediate transmission of neurofibrillary tangles in a transgenic mouse model of Alzheimer's-like tauopathy. J Neurosci 33 (3):1024-1037, doi:10.1523/JNEUROSCl. 2642-12.2013

68. Lasagna-Reeves CA, Sengupta U, Castillo-Carranza D, Gerson JE, Guerrero-Munoz M, Troncoso JC, Jackson GR, Kayed R (2014) The formation of tau pore-like structures is prevalent and cell specific: possible implications for the disease phenotypes. Acta Neuropathol Commun 2(1):56, doi:10.1186/20515960-2-56

69. Lasagna-Reeves CA, Castillo-Carranza DL, Sengupta U, Sarmiento J, Troncoso J, Jackson GR, Kayed R (2012) Identification of oligomers at early stages of tau aggregation in Alzheimer's disease. Faseb J 26(5):1946-1959, doi:10.1096/fj.11199851

70. Ochoa CD, Alexeyev M, Pastukh V, Balczon R, Stevens T (2012) Pseudomonas aeruginosa exotoxin $Y$ is a promiscuous cyclase that increases endothelial tau phosphorylation and permeability. J Biol Chem 287(30):25407-25418, doi:10.1074/jbc.M111.301440

71. Zhu B, Zhang L, Creighton J, Alexeyev M, Strada SJ, Stevens T (2010) Protein kinase A phosphorylation of tau-serine 214 reorganizes microtubules and disrupts the endothelial cell barrier. Am J Physiol Lung Cell Mol Physiol 299 (4):L493-L501, doi:10.1152/ajplung.00431.2009

72. Birukova AA, Birukov KG, Smurova K, Adyshev D, Kaibuchi K, Alieva I, Garcia JG, Verin AD (2004) Novel role of microtubules in thrombin-induced endothelial barrier dysfunction. Faseb J 18(15):1879-1890, doi:10.1096/fj.04-2328com

73. Ghetti B, Piccardo P, Spillantini MG, Ichimiya Y, Porro M, Perini F, Kitamoto T, Tateishi J, Seiler C, Frangione B, Bugiani O, Giaccone G, Prelli F, Goedert M, Dlouhy SR, Tagliavini F (1996) Vascular variant of prion protein cerebral amyloidosis with tau-positive neurofibrillary tangles: the phenotype of the stop codon 145 mutation in PRNP. Proc Natl Acad Sci U S A 93(2):744-748 
74. Williams S, Chalmers K, Wilcock GK, Love S (2005) Relationship of neurofibrillary pathology to cerebral amyloid angiopathy in Alzheimer's disease. Neuropathol Appl Neurobiol 31(4):414-421, doi:10.1111/j.13652990.2005.00663.x

75. Sagare AP, Bell RD, Zlokovic BV (2013) Neurovascular defects and faulty amyloid-beta vascular clearance in Alzheimer's disease. J Alzheimers Dis 33 (Suppl 1):S87-S100, doi:10.3233/JAD-2012-129037

76. Dickson DW (1999) Neuropathologic differentiation of progressive supranuclear palsy and corticobasal degeneration. J Neurol 246(Suppl 2):116-1115

77. van Assema DM, Lubberink M, Rizzu P, van Swieten JC, Schuit RC, Eriksson J, Scheltens P, Koepp M, Lammertsma AA, van Berckel BN (2012) Blood-brain barrier P-glycoprotein function in healthy subjects and Alzheimer's disease patients: effect of polymorphisms in the ABCB1 gene. EJNMMI Res 2(1):57, doi:10.1186/2191-219X-2-57

78. Dickson DW, Rademakers R, Hutton ML (2007) Progressive supranuclear palsy: pathology and genetics. Brain Pathol 17(1):74-82, doi:10.1111/j.17503639.2007.00054.x

79. Forman MS, Zhukareva V, Bergeron C, Chin SS, Grossman M, Clark C, Lee VM, Trojanowski JQ (2002) Signature tau neuropathology in gray and white matter of corticobasal degeneration. Am J Pathol 160(6):2045-2053, doi:10.1016/S0002-9440(10)61154-6

80. Ikeda K, Akiyama H, Kondo H, Haga C, Tanno E, Tokuda T, Ikeda S (1995) Thorn-shaped astrocytes: possibly secondarily induced tau-positive glial fibrillary tangles. Acta Neuropathol 90(6):620-625

81. Shibuya K, Yagishita S, Nakamura A, Uchihara T (2011) Perivascular orientation of astrocytic plaques and tuft-shaped astrocytes. Brain Res 1404:50-54, doi:10.1016/j.brainres.2011.06.014

82. Brochard V, Combadiere B, Prigent A, Laouar Y, Perrin A, Beray-Berthat V, Bonduelle O, Alvarez-Fischer D, Callebert J, Launay JM, Duyckaerts C, Flavell RA, Hirsch EC, Hunot S (2009) Infiltration of CD4+ lymphocytes into the brain contributes to neurodegeneration in a mouse model of Parkinson disease. J Clin Invest 119(1):182-192, doi:10.1172/JCI36470

83. Mandrekar-Colucci S, Landreth GE (2010) Microglia and inflammation in Alzheimer's disease. CNS Neurol Disord Drug Targets 9(2):156-167

84. McGeer PL, McGeer EG (2004) Inflammation and the degenerative diseases of aging. Ann N Y Acad Sci 1035:104-116, doi:10.1196/annals.1332.007

85. Rogers J, Luber-Narod J, Styren SD, Civin WH (1988) Expression of immune system-associated antigens by cells of the human central nervous system: relationship to the pathology of Alzheimer's disease. Neurobiol Aging 9(4):339-349

\section{Submit your next manuscript to BioMed Central and take full advantage of:}

- Convenient online submission

- Thorough peer review

- No space constraints or color figure charges

- Immediate publication on acceptance

- Inclusion in PubMed, CAS, Scopus and Google Scholar

- Research which is freely available for redistribution 